\title{
Alteration of the late endocytic pathway in Charcot-Marie-Tooth type 2B disease
}

\author{
Roberta Romano ${ }^{1}$. Cristina Rivellini ${ }^{2} \cdot$ Maria De Luca ${ }^{1} \cdot$ Rossana Tonlorenzi $^{2} \cdot$ Raffaella Beli $^{1} \cdot$ Fiore Manganelli $^{3}$. \\ Maria Nolano ${ }^{3,4} \cdot$ Lucio Santoro $^{3} \cdot$ Eeva-Liisa Eskelinen $^{5,6} \cdot$ Stefano C. Previtali ${ }^{2} \cdot$ Cecilia Bucci $^{1}$ (1)
}

Received: 17 September 2019 / Revised: 18 March 2020 / Accepted: 24 March 2020 / Published online: 13 April 2020

(c) The Author(s) 2020

\begin{abstract}
The small GTPase RAB7A regulates late stages of the endocytic pathway and plays specific roles in neurons, controlling neurotrophins trafficking and signaling, neurite outgrowth and neuronal migration. Mutations in the $R A B 7 A$ gene cause the autosomal dominant Charcot-Marie-Tooth type 2B (CMT2B) disease, an axonal peripheral neuropathy. As several neurodegenerative diseases are caused by alterations of endocytosis, we investigated whether CMT2B-causing mutations correlate with changes in this process. To this purpose, we studied the endocytic pathway in skin fibroblasts from healthy and CMT2B individuals. We found higher expression of late endocytic proteins in CMT2B cells compared to control cells, as well as higher activity of cathepsins and higher receptor degradation activity. Consistently, we observed an increased number of lysosomes, accompanied by higher lysosomal degradative activity in CMT2B cells. Furthermore, we found increased migration and increased RAC1 and MMP-2 activation in CMT2B compared to control cells. To validate these data, we obtained sensory neurons from patient and control iPS cells, to confirm increased lysosomal protein expression and lysosomal activity in CMT2B-derived neurons. Altogether, these results demonstrate that in CMT2B patient-derived cells, the endocytic degradative pathway is altered, suggesting that higher lysosomal activity contributes to neurodegeneration occurring in CMT2B.
\end{abstract}

Keywords RAB7A $\cdot$ Endocytosis $\cdot$ Lysosome $\cdot$ RAC1 $\cdot$ Migration $\cdot$ EGFR

Electronic supplementary material The online version of this article (https://doi.org/10.1007/s00018-020-03510-1) contains supplementary material, which is available to authorized users.

Cecilia Bucci

cecilia.bucci@unisalento.it

1 Department of Biological and Environmental Sciences and Technologies (DiSTeBA), University of Salento, Lecce, Italy

2 Institute of Experimental Neurology (INSPE), IRCCS San Raffaele Scientific Institute, Milan, Italy

3 Department of Neurosciences, Reproductive Sciences and Odontostomatology, University of Naples "Federico II", Naples, Italy

4 Salvatore Maugeri Foundation, Institute of Telese Terme, Benevento, Italy

5 Institute of Biomedicine, University of Turku, Turku, Finland

6 Molecular and Integrative Biosciences Research Programme, University of Helsinki, Helsinki, Finland

\section{Introduction}

Endocytosis is an extremely regulated process by which cells internalize different plasma membrane components and molecules from the extracellular space [1]. This pathway plays a role in several cellular events, including termination of signaling pathways by targeting signaling receptors to degradation compartments such as late endosomes and lysosomes $[1,2]$. Transport to late endosomes and lysosomes is finely controlled by sequential events and by several cellular proteins, including RAB GTPases, molecular motors and sorting regulators that altogether assure correct shipment to compartments $[1,3]$.

RAB7A, hereafter called RAB7, a ubiquitous RAB GTPase, regulates clustering and fusion of late endosomes and lysosomes in the perinuclear area, controlling biogenesis of and transport to lysosomes, phagolysosomes and autolysosomes [4-8]. Interestingly, several studies demonstrate that RAB7 plays specific roles in neurons, controlling axonal retrograde transport of neurotrophins, neurotrophin receptor signaling, neurite outgrowth and the final phase of immature 
cortical neuron migration [9-14]. Furthermore, RAB7 interacts with and controls assembly of two intermediate filament proteins, peripherin and vimentin, which play an essential role in neurite outgrowth and axonal regeneration, and which also regulate the degradative endocytic pathway, providing positional information for late endocytic organelles and being responsible for their function [15-22].

Notably, a number of studies show that alterations of endocytic traffic and axonal transport are causative of several neurodegenerative diseases, such as Alzheimer's disease, Huntington's disease and amyotrophic lateral sclerosis [23]. In line with these findings, five missense mutations in the RAB7 gene cause Charcot-Marie-Tooth type 2B (CMT2B) disease, a rare inherited autosomal dominant neuropathy affecting the peripheral nervous system [24-27].

CMT2B is one of the numerous forms of CMT disease. It is an axonal neuropathy, characterized by progressive distal weakness and atrophy, accompanied by sensory loss and ulcero-mutilating complications [28-32]. CMT2B is a rare form of CMT and only one Italian family carrying the $\mathrm{RAB} 7{ }^{\mathrm{V} 162 \mathrm{M}}$ mutation has been identified up to now [33].

The biochemical properties of four CMT2B-causing mutants $\left(\mathrm{RAB} 7^{\mathrm{L} 129 \mathrm{~F}}, \mathrm{RAB} 7^{\mathrm{K} 157 \mathrm{~N}}, \mathrm{RAB} 7^{\mathrm{N} 161 \mathrm{~T}}\right.$ and $\mathrm{RAB} 7^{\mathrm{V} 162 \mathrm{M}}$ ) have been previously investigated, demonstrating that these mutants show higher nucleotide $K_{\text {off }}$ compared to the wild-type protein, and, therefore, release nucleotides faster [34-36]. As in the cell GTP concentration is higher than GDP, CMT2B mutants are mostly in the GTP-bound form, and were initially predicted to be active mutants [36]. However, these mutant proteins also release GTP faster than the wt protein, thus displaying a reduced GTPase activity per binding event [34-36], and, for this reason, they could inhibit activation of specific effectors while inducing activation of others. This hypothesis is corroborated by data in Drosophila, where neurodegeneration occurring in CMT2B is due to partial loss of function, and in zebrafish where axon growth and guidance defects are caused by a gain of function mechanism [37-39]. Therefore, CMT2B-causing mutations are neither "loss of function" nor "gain of function", but they behave as either inhibitory or activating, depending on kinetic requirements of the processes controlled by RAB7.

Importantly, the expression of CMT2B-causing RAB7 mutants alters several neuronal processes, modifying neurotrophin trafficking and, as a consequence, neurotrophin signaling pathways, thus resulting in inhibition of neurite outgrowth [40-42].

In this work, we analyzed different aspects of the endocytic pathway in skin fibroblasts and iPS-derived sensory neurons. Interestingly, we found that patient-derived CMT2B cells display greater expression of lysosomal markers as well as higher lysosomal activity compared to control cells, suggesting that these alterations could contribute to neurodegeneration.

\section{Materials and methods}

\section{Cells and reagents}

Dermal fibroblasts derived from two healthy individuals (control fibroblasts) and from three CMT2B patients belonging to the same Italian family carrying the $\mathrm{RAB} 7^{\mathrm{V} 162 \mathrm{M}}$ mutation were obtained as previously described [43]. After informed consent for pathological diagnosis, samples were anonymously encoded to protect patient confidentiality and used under protocols approved by the Azienda Ospedaliera Universitaria "Federico II" Ethics Committee (Ethical Committee Approval Protocol \# 107/05). Fibroblasts were cultured in Dulbecco's modified Eagle's medium (DMEM) supplemented with 15\% fetal bovine serum (FBS), $2 \mathrm{mM}$ L-glutamine, $100 \mathrm{U} / \mathrm{ml}$ penicillin and $10 \mathrm{mg} / \mathrm{ml}$ streptomycin in a $5 \% \mathrm{CO}_{2}$ incubator at $37^{\circ} \mathrm{C}$. Chemicals and tissue culture reagents were from Sigma-Aldrich (St-Louis, MO, USA). HeLa cells were maintained in DMEM supplemented with $10 \%$ FBS, $2 \mathrm{mM}$ L-glutamine, $100 \mathrm{U} / \mathrm{ml}$ penicillin and $10 \mathrm{mg} / \mathrm{ml}$ streptomycin in a $5 \% \mathrm{CO}_{2}$ incubator at $37^{\circ} \mathrm{C}$.

\section{Antibodies}

Primary antibodies used in this study were: mouse monoclonal anti-RAB7 (1:500, sc-376362), anti-RAB9 (1:200, sc-74482), anti- $\beta$-actin $(1: 1000$, sc-47778), anti-RACGAP1 (1:200, sc-271110), anti-OCT3/4 (1:200; sc-5279) and anti $\operatorname{EAP30}(1: 200, \mathrm{sc}-100892)$, rabbit polyclonal anti-RAB4 (1:200, sc-312), anti-RAB5 (1:200, sc-309), anti-ERK1 (1:200, sc-93), anti-HA (1:100, sc-805) and anti-pAKT (1:200, sc-7985-R), goat polyclonal anti-cathepsin D (1:500, sc-6486) from Santa Cruz Biotechnology, (Dallas, TX, USA); mouse monoclonal anti-tubulin $(1: 10,000, T 5168)$ and anti-Smooth Muscle Actin (1:200; A2547) from Sigma-Aldrich (St. Louis, MO, USA); mouse monoclonal anti-cytokeratin CK8/18 (1:400; NCL-L-5D3) from Leica (Wetzlar, Germany); mouse monoclonal antiLAMP2 (1:5000, H4B4), developed by J.T. August and J.E.K. Hildreth and obtained from the Developmental Studies Hybridoma Bank, (Iowa City, IA 52242); rabbit polyclonal anti-CI-MPR (1:2000, ab32815), anti-TSG101 (1:500, ab30871) anti-LAMP1 (1:4000, for immunoblot analysis and 1:1000 for immunofluorescence analysis, ab24170) and goat polyclonal anti-CGRP (1:200; ab36001) from Abcam (Cambridge, UK); rabbit polyclonal anti-peripherin (1:100, AB1530) and anti-Brn3a (1:100; AB5945) from Merck Millipore (Burlington, MS, USA); sheep polyclonal anti-TGN46 (1:500, AHP500) from Bio-Rad (Hercules, CA, USA); sheep polyclonal anti 
EGFR (1:1000, 20-ES04) from Fitzgerald (North Acton, MS, USA); rabbit monoclonal anti-AKT $(1: 1000,4691)$ and phospho-p44/42 (Erk 1/2) (1:2000, 4370) from Cell Signaling Technology (Leiden, The Netherlands); mouse monoclonal anti-RAC1 (1:600, ARC03) from Cytoskeleton (Denver, CO, USA); rabbit polyclonal anti-Nanog (1:100; RCAB0002P-F) from ReproCELL (Glasgow, UK); rabbit polyclonal anti-Pax-6 (1:100; PRB-278P) from Covance (Princeton, NJ, USA); chicken polyclonal anti-Neurofilament M (1:1000; 822701) from BioLegend (San Diego, CA, USA); rabbit polyclonal anti-ARHGEF6 (1:1000; A302-558A) from Bethyl Laboratories (Montgomery, TX, USA). Secondary antibodies conjugated to fluorochromes (used at 1:600 dilution) or HRP (used at 1:5000 dilution) were from Invitrogen (Carlsbad, CA, USA), Fitzgerald, SouthernBiotech (Birmingham, AL, USA) or Jackson ImmunoResearch (Cambridgeshire, UK).

\section{Plasmids}

Plasmids encoding HA-tagged RAB $7^{\mathrm{WT}}$ and the CMT2Bcausing $\mathrm{RAB} 7^{\mathrm{V} 162 \mathrm{M}}$ mutant protein have been previously described [36]. The pcDNA3-HA plasmid was constructed by inserting a DNA sequence coding for a $2 x H A-t a g$ into the KpnI restriction site of the pCDNA3.1 (Invitrogen, V79020) and it was used as empty vector in control transfections.

\section{Induced pluripotent stem cells generation}

iPSCs were generated reprogramming fibroblasts from healthy controls and CMT2B patients carrying the $\mathrm{RAB} 7^{\mathrm{V} 162 \mathrm{M}}$ mutation by Sendai viral transduction of the transcription factors OCT4, SOX2, KLF4, and c-MYC (CytoTune2.0-iPS Sendai Reprogramming Kit, Thermo Fisher, Waltham, MS, USA). iPSCs were then tested for Sendai virus clearance (CytoTune2.0-iPS Sendai Reprogramming Kit, Thermo Fisher) and pluripotency (Trilineage differentiation Kit, Stem Cell Technologies, Vancouver, Canada). Cells were regularly screened and confirmed negative for mycoplasma during both maintenance and differentiation (MycoAlert kit, Lonza, Basel, Switzerland).

\section{Induced pluripotent stem cells maintenance and differentiation in dorsal root ganglia (DRG) sensory neurons}

iPSCs were maintained in feeder-free conditions using mTeSR1 medium (Stem Cell Technologies) on hES qualified Matrigel (Corning, Corning, NY, USA) coated plates. At $80-90 \%$ of confluency, iPSCs were passaged using $0.5 \mathrm{mM}$ EDTA in PBS (Sigma-Aldrich) or ReLeSR (Stem Cell Technologies), in the presence of ROCK inhibitor (Stem Cell Technologies). Prior to differentiation, iPSCs were single cell dissociated with Accumax (Sigma-Aldrich) and plated onto hES qualified Matrigel coated six-well plates in the presence of ROCK inhibitor. Cells were grown in mTeSR 1 medium for $24 \mathrm{~h}$, then shifted to MEF-CM (Mouse embryo fibroblasts-conditioned medium) produced according to Lee et al. [44], supplemented with $10 \mathrm{ng} / \mathrm{ml} \mathrm{bFGF}$ (Thermo Fisher). At approximately $40-50 \%$ of confluency (usually 24/48 $\mathrm{h}$ after the shift to CM medium), differentiation was started [45, 46]. The medium was replaced with KSR medium high glucose DMEM (Thermo Fisher) supplemented with $15 \%$ KSR (KO serum replacement, Thermo Fisher), $1 \times$ L-glutamine (Thermo Fisher), $1 \times$ Pen/Strep (Thermo Fisher), $1 \times$ sodium pyruvate (Thermo Fisher), non-essential amino acids (Thermo Fisher), and $100 \mu \mathrm{M}$ 2-mercaptoethanol (Thermo Fisher). Smad inhibitors $10 \mu \mathrm{M}$ SB431542 (Tocris, Bristol, UK) + $0.1 \mu M$ LDN193189 (Stemgent, Cambridge, MS, USA) were added to the medium from day \#0 to day \#5 (see Supplemental Table 1). Three more small molecules $3 \mu \mathrm{M}$ CHIR99021 (Tocris), $10 \mu \mathrm{M}$ DAPT $10 \mu \mathrm{M}$ (Tocris), and $10 \mu \mathrm{M}$ SU5402 (Tocris) were added from day \#2 to day \#12. If overconfluent, cultures were split on day \#2/day \#3 to guarantee optimal differentiation [46]. From day \#5 to day \#12, the KSR medium was gradually transitioned to N2B27 medium (Neurobasal, Thermo Fisher) and added with $1 \% \mathrm{~N}_{2}$ supplement (Thermo Fisher), 1\% B27 supplement (Thermo Fisher), $1 \times$ glutamine (Thermo Fisher), and $1 \times$ pen strep (Thermo Fisher). On day \#11, young neurons were detached with TrypLE Express (Thermo Fisher) and replated on GFR (growth factor reduced) Matrigel (Corning)-coated coverslips. On day \#13, the cultures were shifted to neural differentiation medium (Neurobasal, Thermo Fisher), supplemented with $1 \% \mathrm{~N}_{2}$ supplement (Thermo Fisher), 1\% B27 (Thermo Fisher), 1\% Pen-Strep (Thermo Fisher), 1\% L-glutamine (Thermo Fisher), $25 \mathrm{ng} / \mathrm{ml}$ GDNF (Peprotech, London, UK), $25 \mathrm{ng} /$ ml BDNF (Peprotech), 25 ng/ml NGF (Peprotech), $25 \mathrm{ng} /$ ml NT3 (Peprotech), and $1 \mu \mathrm{M}$ laminin (Sigma-Aldrich). CHIR99021 was added to neural differentiation medium for 3 days (from day \#13 to day \#15). $1 \mu \mathrm{M} \mathrm{AraC} \mathrm{(Sigma-}$ Aldrich) was included in differentiation medium for 1 week (from day \#13 to day \#20) to kill off dividing cells. The treatment with AraC was repeated, if necessary, every other week (up to 3 cycles). Differentiation was usually extended from 2 to 4 weeks.

\section{Transfection and RNA interference}

Transfection of HeLa cells was performed using Metafectene Pro from Biontex (Martinsried, Germany), as indicated by the manufacturer. After $20 \mathrm{~h}$ of transfection, cells were processed for DQ-BSA dequenching assay. Transfection of cells with siRNA was performed using Metafectene SI from Biontex (Martinsried, Germany) as indicated by the 
manufacturer. Cells were analyzed after 5 days of transfection. Small interfering RNAs (siRNAs) were purchased from MWG-Biotech (Ebersberg, Germany).

Rab7a siRNA efficiency in silencing was reported previously [36]: sense sequence 5'-GGAUGACCUCUAGGA AGAATT-3' and antisense sequence 5'-UUCUUCCUAGAG GUCAUCCTT-3'. Control RNA was used as a negative control: sense sequence 5'-ACUUCGAGCGUGCAUGGCUTT$3^{\prime}$ and antisense sequence 5'-AGCCAUGCACGCUCGAAG UTT-3'.

\section{EGF internalization and EGFR degradation assays}

For the EGF internalization assay, control and CMT2B skin fibroblasts were incubated overnight in starvation medium (0.5\% BSA, 20 mm HEPES, pH 7.3, in DMEM). Cells were subsequently incubated for $1 \mathrm{~h}$ at $4{ }^{\circ} \mathrm{C}$ with $0.8 \mathrm{mg} / \mathrm{ml}$ rhodamine-labeled EGF (Thermo Fisher, E3481) in starvation medium and then washed several times with starvation medium. After incubation at $37^{\circ} \mathrm{C}$ in complete DMEM medium for different time points ( $30 \mathrm{~min}, 1 \mathrm{~h}$ and $2 \mathrm{~h}$ ), cells were fixed, mounted on slides, and processed for confocal microscopy. Zen 2011 software (Carl Zeiss, Oberkochen, Germany) was used for image capture and to calculate weighted colocalization coefficient of EGF and LAMP1. For EGFR degradation assay, control and CMT2B skin fibroblasts were incubated for $1 \mathrm{~h}$ at $37{ }^{\circ} \mathrm{C}$ with serum- and antibiotic-free DMEM and $10 \mu \mathrm{g} / \mathrm{ml}$ cycloheximide, then stimulated with EGF (50 ng/ml) for different times $(15,60,180$, $360 \mathrm{~min}$ ) and lysed with RIPA buffer (50 mM Tris-HCl, $\mathrm{pH}$ 8.0 , with $150 \mathrm{mM}$ sodium chloride, $1.0 \%$ Igepal CA-630 (NP-40), $0.5 \%$ sodium deoxycholate, and $0.1 \%$ sodium dodecyl sulfate) plus protease inhibitor cocktail (Roche, Mannheim, Germany). The levels of degraded EGFR were determined by western blotting. When indicated, $100 \mu \mathrm{M}$ chloroquine was added to the cells $3 \mathrm{~h}$ before harvesting.

\section{Analysis of cathepsin D synthesis}

Cells were treated with $10 \mu \mathrm{g} / \mathrm{ml}$ cycloheximide (to inhibit protein synthesis) for $50 \mathrm{~h}$, lysed with $2 \times$ Laemmli buffer supplemented with DTT (dithiothreitol) and subjected to western blot analysis. Bands were quantified by densitometry using ImageJ software (National Institutes of Health).

\section{Cathepsin activity assays}

Cathepsin D Activity Fluorometric Assay (K143-100, BioVision, Milpitas, CA, USA) utilizes the cathepsin-D substrate sequence GKPILFFRLK(Dnp)-D-R-NH2 labeled with fluorescent MCA (7-methoxycoumarin-4-acetic acid). $2 \times 10^{4}$ control and CMT2B cells were collected and read in a fluorometer equipped with a $328-\mathrm{nm}$ excitation filter and 460-nm emission filter. Cathepsin D activity was expressed by relative fluorescence units (RFU) per million cells and by RFU fold increase of CMT2B fibroblasts against control fibroblasts. Cathepsin B and Cathepsin L Activity Assay Kits (BioVision, K140-100 e K142-100) utilize, respectively, the preferred cathepsin-B RR and cathepsin-L FR substrate sequence labeled with fluorescent AFC (7-amino4-trifluoromethylcoumarin). $2 \times 10^{4}$ control and CMT2B fibroblasts were collected and read in a fluorometer equipped with a 400-nm excitation filter and 505-nm emission filter. Fold-increase in cathepsin-B or cathepsin-L activity was determined by comparing the relative fluorescence units (RFU) measured in CMT2B and control fibroblasts.

\section{DQ-BSA dequenching assay}

Cells were grown on glass coverslips and treated with DQBSA. Fibroblasts were treated with DQ Red BSA $(10 \mu \mathrm{g} / \mathrm{ml}$, Thermo Fisher, D12051) for $48 \mathrm{~h}$, neurons with DQ Green BSA ( $50 \mu \mathrm{g} / \mathrm{ml}$, Thermo Fisher, D12050) for $24 \mathrm{~h}$ and HeLa cells with DQ Green BSA $(10 \mu \mathrm{g} / \mathrm{ml})$ for $6 \mathrm{~h}$. Fluorescence was quantified with Zeiss LSM 700 confocal microscope.

\section{Western blotting}

Control and CMT2B fibroblasts and neurons were lysed with Laemmli buffer $[100 \mathrm{mM}$ Tris-HCl, $\mathrm{pH} 6.8,4 \%$ (w/v) SDS, $0.2 \%$ (w/v) bromophenol blue, $20 \%$ glycerol and $200 \mathrm{mM}$ DTT (dithiothreitol)]. Lysates were loaded on SDS-PAGE and separated proteins were transferred onto PVDF membrane (Merck Millipore). The filter was blocked in 5\% milk in PBS for $30 \mathrm{~min}$ at room temperature, incubated with the appropriate primary antibody and then with a secondary antibody conjugated with HRP (diluted 1:5000). When phosphorylation was monitored, cells were lysed in the presence of phosphatase inhibitors (PhosSTOP, Roche). Bands were visualized using Western blot Luminol Reagent (Santa Cruz) or Western Bright ECL kit (Advansta, Menlo Park, CA, USA) or ClarityMax (Bio-Rad). The signal was captured on a film, avoiding saturation, to ideally compare samples in the linear range of detection. To prevent saturation of the signal, we previously estimated proper loading amounts. To reduce variability, we did not quantify signals that decayed too quickly and we avoided comparing very weak bands that may be outside the linear range. Films were then scanned at 600 dpi resolution and quantified using ImageJ (National Institutes of Health). Each band was quantified selecting rectangular areas and subtracting the film background. Bands relative to the protein of interest and to the related tubulin loading control were quantified. Measurement of each protein was then normalized on the related tubulin loading control and CMT2B normalized measurements were compared 
to control normalized measurements obtained from the same gel.

\section{Confocal immunofluorescence microscopy}

Fibroblasts grown on coverslips were permeabilized, fixed and incubated with primary and secondary antibodies as described previously [47] and viewed with Zeiss LSM 700 confocal microscope. HeLa cells were fixed for $20 \mathrm{~min}$ in $3 \%$ paraformaldehyde, permeabilized with $0.1 \%$ TX100 in PBS and then incubated with primary and secondary antibodies diluted in $0.1 \%$ saponin in PBS. Then, washing, cells were stained with DAPI and coverslips were mounted and viewed with Zeiss LSM 700 confocal microscope.

iPS cells or peripheral neurons were fixed for $20 \mathrm{~min}$ in $4 \%$ paraformaldehyde, blocked and permeabilized for 20 min with $10 \%$ NGS, $1 \%$ BSA, and $0.1 \%$ TX100. Alternatively, cells were fixed and permeabilized for $10 \mathrm{~min}$ in ice-cold methanol at $-20^{\circ} \mathrm{C}$. After incubation with primary antibody overnight at $4{ }^{\circ} \mathrm{C}$, the coverslips were washed, incubated with the secondary antibody for $30 \mathrm{~min}$, washed, and mounted with DAPI (H-1200, Vector Laboratories, Burlingame, CA, USA) and viewed with Leica SP5 confocal microscope.

\section{Electron microscopy}

Cells were fixed in $2 \%$ glutaraldehyde in $0.2 \mathrm{M}$ Hepes, $\mathrm{pH}$ 7.4 , at room temperature for $2 \mathrm{~h}$. During fixation, the cells were scraped off the culture dish and pelleted. After postfixation in $1 \%$ osmium tetroxide, cells were dehydrated in ethanol and embedded in epoxy resin. Sections were cut with a diamond knife and contrasted with uranyl acetate and lead citrate. Microscopy was performed with a Jeol JEM 1400 Plus transmission electron microscope.

\section{Real-time PCR}

For RT-PCR on fibroblasts, RNA was isolated from cells using an RNeasy Micro kit according to the manufacturer's instructions (Qiagen, Hilden, Germany). For RNA retrotranscription protocol, we used SuperScript II Reverse Transcriptase (Invitrogen) according to the manufacturer's instructions. Briefly, a mixture $(12 \mu \mathrm{l})$ containing $4 \mu \mathrm{g}$ of RNA, $10 \mathrm{mM}$ of deoxynucleotides and $40 \mathrm{ng}$ of random primers (Promega, Madison, WI, USA) was heated at $65^{\circ} \mathrm{C}$ for $5 \mathrm{~min}$. First-strand cDNA synthesis was carried out with SuperScript II Reverse Transcriptase in the presence of dithiothreitol $(0.01 \mathrm{M})$ and ribonuclease inhibitor $(40 \mathrm{U}$, RNaseOUT, Invitrogen) at $42{ }^{\circ} \mathrm{C}$ for $50 \mathrm{~min}$. Reactions were stopped by heat inactivation at $70{ }^{\circ} \mathrm{C}$ for $15 \mathrm{~min}$.
Quantitative real-time PCR was carried out with Power SYBR Green (Applied Biosystems, Foster City, USA) using Applied Biosystems 7900HT Fast Real-time PCR System.

The primers used were:

GAPDH: forward: 5'-GGTGGTCTCCTCTGACTT CAACA-3',

reverse: 5'-GTTGCTGTAGCCAAATTCGTTGT-3'.

Cathepsin B: forward: 5'-CTGTCGGATGAGCTGGTC

AAC-3',

reverse: 5'-TCGGTAAACATAACTCTCTGGGG-3'.

Cathepsin D: forward: 5'-CAGAAGCTGGTGGACCAG

AAC-3',

reverse: 5'-TGCGGGTGACATTCAGGTAG-3'.

Cathepsin L: forward: 5'-GCTAATGACACCGGCTTT

GT-3',

reverse: 5'-TTTCAAATCCGTAGCCAACC-3'.

LAMP1: forward: 5'-ACGTTACAGCGTCCAGCT

CAT-3',

reverse: 5'-TCTTTGGAGCTCGCATTGG-3'.

LAMP2: forward: 5'-TGCTGGCTACCATGGGGC TG-3',

reverse: 5'-GCAGCTGCCTGTGGAGTGAGT-3'.

These were purchased from Eurofins Genomics (Ebersberg, Germany).

The thermal profile used for Real-time PCR was as follows: 1 cycle of $2 \mathrm{~min}$ at $50{ }^{\circ} \mathrm{C} ; 1$ cycle of $10 \mathrm{~min}$ at $95^{\circ} \mathrm{C}$; 40 cycles of $15 \mathrm{~s}$ at $95{ }^{\circ} \mathrm{C}, 1 \mathrm{~min}$ at $55^{\circ} \mathrm{C} ; 1$ cycle of $15 \mathrm{~s}$ at $95{ }^{\circ} \mathrm{C}$ and $15 \mathrm{~s}$ at $60{ }^{\circ} \mathrm{C}$. The specificity of PCR products was checked by performing a melting-curve test. The relative expression level was calculated using the comparative $C_{\mathrm{T}}$ method and expressed as a "fold change". The quantitative values were obtained from the mean minimal cycle threshold $\left(C_{\mathrm{T}}\right)$ calculated from triplicate reactions. The fold change, measured as the amount of target gene normalized to the endogenous reference gene GAPDH, was given by $2^{-\Delta \Delta \mathrm{C}}$, where $\Delta C=C_{\mathrm{Ttarget}}-C_{\mathrm{TGAPDH}}$ and $\Delta \Delta \mathrm{CT}=\Delta_{\text {CTsample }}-\Delta \mathrm{C}_{\text {control }}$. Negative fold change was calculated using the formula $-1 / 2^{-\Delta \Delta C}$. The relative quantification was considered significant when there was a minimum of twofold change.

For RT-PCR on iPS or iPS-derived cells, in brief, iPS cell clones and differentiated iPSCs tested for pluripotency (Trilineage differentiation Kit, Stem Cell Technologies) were homogenized with TRIzol reagent (15596026; Invitrogen) and total RNA was extracted with chloroform and precipitated with isopropanol. A portion (500 ng) of total RNA was reverse transcribed using High-Capacity cDNA Reverse Transcription Kits (4368814, Applied Biosystems), according to the manufacturer's instructions. Semiquantitative RTPCR analyses were performed with GoTaq G2 Flexi DNA Polymerase (M7805, Promega). Primer sequences are shown in Supplemental Table 2, while primers used to test iPSCs 
for Sendai virus clearance derived from CytoTune2.0-iPS Sendai Reprogramming Kit (Thermo Fisher).

\section{Wound-healing assay}

Confluent monolayer of fibroblasts was wounded with a pipette tip. The cell debris was washed out with PBS. Cells were imaged at the moment of the scratch (T0) and after $15 \mathrm{~h}$ using a $10 \times$ objective of EVOS digital microscope. Accumulated distance was measured using photoshop software as the total distance that cells traveled in a certain amount of time.

\section{Gelatin zymography}

The conditioned medium was collected from cells cultured for $24 \mathrm{~h}$ in serum-free medium, the sample was concentrated using Amicon ${ }^{\circledR}$ Ultra (Merck Millipore) and quantified by Bradford assay. Each sample was adjusted to $15 \mu \mathrm{g} / \mathrm{ml}$, and $10 \mu \mathrm{l}$ was loaded in non-reduced protein sample buffer on 7.5\% SDS-PAGE gel containing $1 \mathrm{mg} / \mathrm{ml}$ gelatin (Biorad). The gel was washed in a specific buffer $(2.5 \%$ Triton X-100, $50 \mathrm{mM}$ Tris- $\mathrm{HCl} \mathrm{pH} 7.5,5 \mathrm{mM} \mathrm{CaCl}_{2}, 1 \mu \mathrm{M} \mathrm{ZnCl}_{2}$ ) to remove SDS and then three times in distilled water. After washing, the gel was incubated at $37^{\circ} \mathrm{C}$ for $24 \mathrm{~h}$ in a buffer containing $1 \%$ Triton $\mathrm{X}-100,50 \mathrm{mM}$ Tris- $\mathrm{HCl} \mathrm{pH} 7.5$, $5 \mathrm{mM} \mathrm{CaCl}_{2}, 1 \mu \mathrm{M} \mathrm{ZnCl}_{2}$ and then was stained with $0.5 \%$ Coomassie Blue R-250 (Sigma-Aldrich) and destained in $40 \%$ methanol and $10 \%$ acetic acid.

\section{Rac1 activity assay}

Rac1 activity was tested following the manufacturer's protocol with Rac1 Pull-down Activation Assay Biochem Kit (BK035, Cytoskeleton). Briefly, lysates were mixed with GST-Pak-PBD beads for $1 \mathrm{~h}$ at $4{ }^{\circ} \mathrm{C}$. After washing, the pelleted beads were resuspended in Laemmli sample buffer and subjected to SDS-polyacrylamide gel electrophoresis. GTP-bound Rac1 was detected by western blot analysis using anti-Rac1 antibody. The total amount of Rac1 was detected by immunoblotting of the whole cell lysates.

\section{Teratoma formation}

iPSCs were preincubated with mTeSR1 (Stem Cell Technologies), added with ROCK inhibitor (Stem Cell Technologies) for $1 \mathrm{~h}$, harvested by Accumax (Sigma-Aldrich) treatment, collected into tubes, and centrifuged, and the pellets were suspended in PBS $1 \times$ (Sigma-Aldrich) with ROCK inhibitor. One-third of the cells from a confluent $35 \mathrm{~mm}$ dish was injected in the testis of 8 weeks old Fox Chase SCID Beige mice (Strain Code: 250, Charles River). Six weeks after injection, tumors were dissected and fixed with formaldehyde solution. Paraffin-embedded tissue was sliced and stained with hematoxylin and eosin. All animal experiments were approved and performed in compliance with the guidelines of San Raffaele Institutional Animal Care and Use Committee.

\section{DNA sequence analysis of RAB7}

Genomic DNA was extracted from pelleted neurons using GenElute Mammalian Genomic DNA Miniprep Kit (SigmaAldrich) according to the manufacturer's protocol. $100 \mathrm{ng}$ of genomic DNA was amplified by PCR using the following primers for exon 4: 5' CTGTGTCCTCACCTGTACTACC $3^{\prime}$ and 5' GAAAAGAGTGGGTTAGGGAAGAAG 3'. PCR conditions for this reaction are: $94{ }^{\circ} \mathrm{C}$ for $7 \mathrm{~min},\left(94{ }^{\circ} \mathrm{C}\right.$ for $1 \mathrm{~min}, 55^{\circ} \mathrm{C}$ for $30 \mathrm{~s}, 72{ }^{\circ} \mathrm{C}$ for $\left.45 \mathrm{~s}\right) \times 30$ cycles followed by a final step at $72{ }^{\circ} \mathrm{C}$ for $7 \mathrm{~min}$. PCR products were loaded on agarose gel and extracted using QIAEX II Gel Extraction Kit (Qiagen, Hilden, Germany). Samples were shipped to Eurofins Genomics (Ebersberg, Germany) for sequencing.

\section{Neurite length analysis}

Neurite length was measured by IncuCyte ${ }^{\circledR}$ S3 Live-Cell Analysis System (Essen BioSCience). Briefly, young neurons were plated in 24-well plate (20,000 cells/well). Bright field (contrast) real-time automated acquisition and measurements for live cells were performed every $4 \mathrm{~h}$ for the first six consecutively days after neuron plating. Two wells per clones were plated and sixteen field per well were analyzed (objective 20x). Neurite length was measured as detected by the IncuCyte Zoom software as the total combined length of all neurites $(\mathrm{mm})$ detected per $\mathrm{mm}^{2}$. All data are expressed relative to the respective day 0 of maturation. Each group is represented by mean \pm SEM $(n=32)$.

\section{Statistical analysis}

Data were statistically analyzed using Student's $t$ test and Mann-Whitney $U$ - test (GraphPad Prism4 software) $\left({ }^{*} p<0.05,{ }^{* *} p<0.01\right.$ and $\left.p<0.001\right)$. Error bars represent SEM. Experiments were performed at least in triplicate.

\section{Results}

\section{Late endocytic protein expression is altered in CMT2B fibroblasts}

To investigate possible endocytic and lysosomal defects in CMT2B, we used previously isolated dermal fibroblasts from a CMT2B patient carrying the $\mathrm{RAB} 7^{\mathrm{V} 162 \mathrm{M}}$ mutation and from a healthy age- and sex-matched control [43]. 
We analyzed first the expression of early endocytic RABs and found comparable amounts of RAB5, a protein controlling early endosomal homotypic fusion and transport from plasma membrane to early endosome [47, 48], as well as of RAB4, a protein regulating different steps of endocytic recycling [49] (Fig. 1a). Next, we looked at late endocytic RAB proteins, such as RAB7 and RAB9, whose abundance increases during early to late endosome transition $[1,50]$. Similar amounts of RAB7, which is mutated in CMT2B neuropathy, were found in CMT2B compared to control fibroblasts (Fig. 1a). However, we observed a strong increase in the levels of RAB9 (Fig. 1a) of about twofold in
CMT2B compared to control cells. Subsequently, we investigated the abundance of other late endosomal and lysosomal markers such as lysosomal associated membrane protein 1 and 2 (LAMP1 and LAMP2) $[1,51]$ in fibroblasts derived from three CMT2B patients of the same Italian family [33] and from two healthy individuals. We observed that, compared to the controls, all CMT2B patients showed higher abundance of LAMP1 and LAMP2, although to a different extent (Fig. 1b, c). We then silenced RAB7 in CMT2B fibroblasts and observed reduced abundance of LAMP1, thus suggesting that the different expression of LAMP proteins in CMT2B cells is most likely related to RAB7 (Fig. 1d). (a)

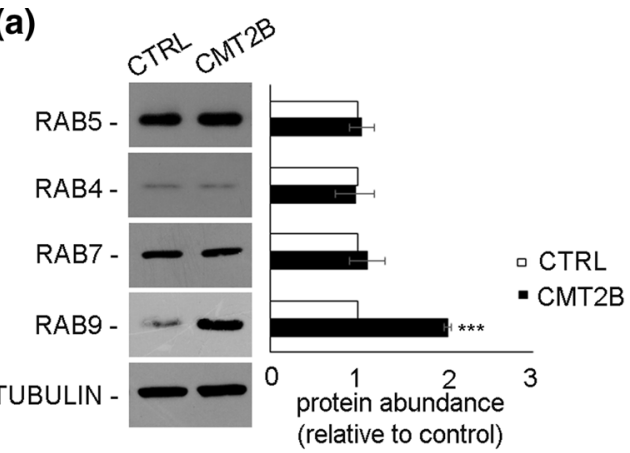

(b)

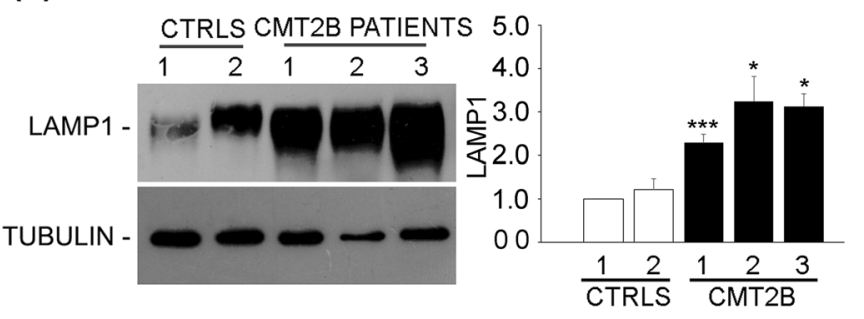

(c)

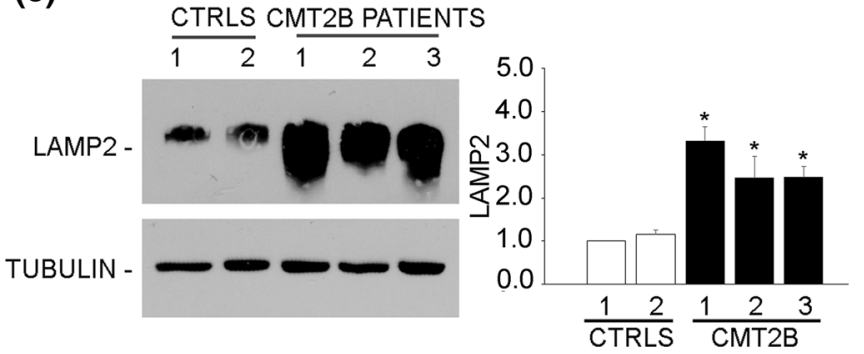

(d)

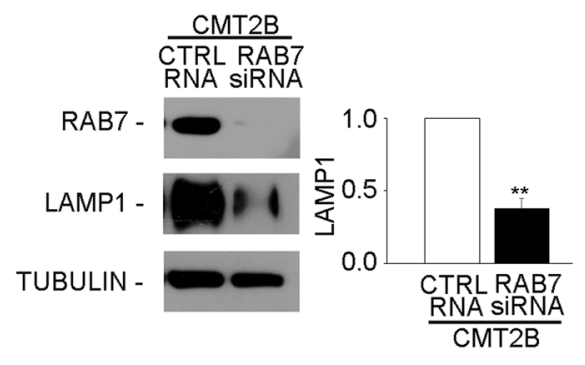

(e)

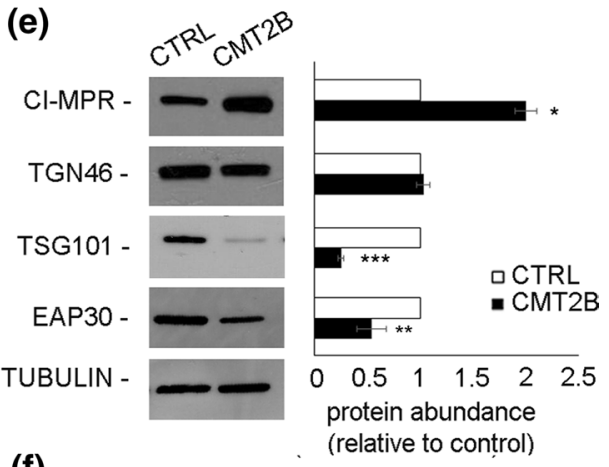

(f)
Fig. 1 Analysis of endosomal and lysosomal markers in control and CMT2B fibroblasts. a Lysates of control and CMT2B patient 1-derived skin fibroblasts carrying the $\mathrm{RAB} 7^{\mathrm{V} 162 \mathrm{M}}$ mutation were analyzed by immunoblotting using anti-RAB5, anti-RAB4, antiRAB7 and anti-RAB9. b, $\mathbf{c}$ Lysates of two controls and three CMT2B skin fibroblasts carrying the $\mathrm{RAB} 7^{\mathrm{V} 162 \mathrm{M}}$ mutation were analyzed by immunoblotting using anti-LAMP1 (b) and anti-LAMP2 (c) antibodies. d CMT2B fibroblasts were silenced for RAB7 and then LAMP1 abundance was analyzed by immunoblotting using anti-LAMP1 antibody. e Lysates of control and CMT2B patient 1-derived skin fibroblasts were analyzed by immunoblotting using anti-CI-MPR, anti-TGN46, anti-TSG101 and anti-EAP30 antibodies. Bands were quantified using NIH ImageJ and normalized against tubulin. $f$ The amount of LAMP1 and LAMP2 transcripts was quantified, compared to the GAPDH transcript as control, using real-time PCR in control and CMT2B patients-derived fibroblasts. All data represent the mean \pm SEM of at least three experiments. Statistical analysis was performed using Student's $t$ test with control fibroblasts as referring sample. * $p<0.05 ; * * p<0.01 ; * * * p<0.001$ 
We then looked at the expression of cation independent mannose-6-phopshate receptor (CI-MPR), a protein involved in transport between Golgi and endosomes, and TGN46, localized to the trans-Golgi network [51-53]. We found that, in CMT2B fibroblasts, the expression of CI-MPR was twofold higher than in control cells (Fig. 1e), while the expression of TGN46 did not change (Fig. 1e).

Sorting events play a crucial role in endocytosis and control correct cargo shipment to lysosomes. Among proteins important for sorting at the level of early endosomes, endosomal sorting complex required for transport (ESCRT) proteins are fundamental for targeting signaling receptors to degradation [54]. Therefore, we decided to investigate the abundance of some of these proteins in CMT2B cells. We found that tumor susceptibility gene 101 (TSG101) was strongly decreased in CMT2B fibroblasts compared to control cells (Fig. 1e), while the expression of ELL (eleven-nineteen lysine-rich leukemia) associated protein 30 (EAP30), the homolog of yeast VPS22, was about $40 \%$ lower in CMT2B fibroblasts (Fig. 1e), suggesting that ESCRT proteins are down-regulated in CMT2B.

To establish whether the observed changes in the amount of late endosomal and lysosomal markers were a consequence of mRNA abundance, we measured LAMP1 and LAMP2 mRNA expression using real-time PCR (Fig. 1f). As the relative quantification is considered significant when there is minimum of twofold change, the mRNA levels of LAMP1 and LAMP2 were not significantly changed (Fig. 1f).

Altogether, these results indicate that in CMT2B fibroblasts, the abundance of early endocytic markers is not affected, the expression of sorting proteins regulating the lysosomal biogenesis is reduced, while the expression of lysosomal protein is increased, suggesting that the late endocytic pathway is altered and that these changes are due to modified RAB7 activity.

\section{CMT2B cells have more lysosomes}

We next investigated the abundance of lysosomes in CMT2B cells by immunofluorescence analysis. In control cells, using antibodies against LAMP1, a marker of late endosome and lysosomes, we observed, as expected the presence of many LAMP1-positive organelles mostly concentrated around the nucleus (Fig. 2a). Staining of CMT2B cells revealed a similar distribution, but a stronger staining of these structures present in the perinuclear area (Fig. 2a), as confirmed by quantification (Fig. 2a).

Immunoblotting (Fig. 1b, c) and immunofluorescence data (Fig. 2a) suggest that the amount of lysosomes may be increased in patient cells. To investigate this, we performed electron microscopy, demonstrating that patient cells were actually filled with lysosomes (Fig. 2b). Quantification of the (a)
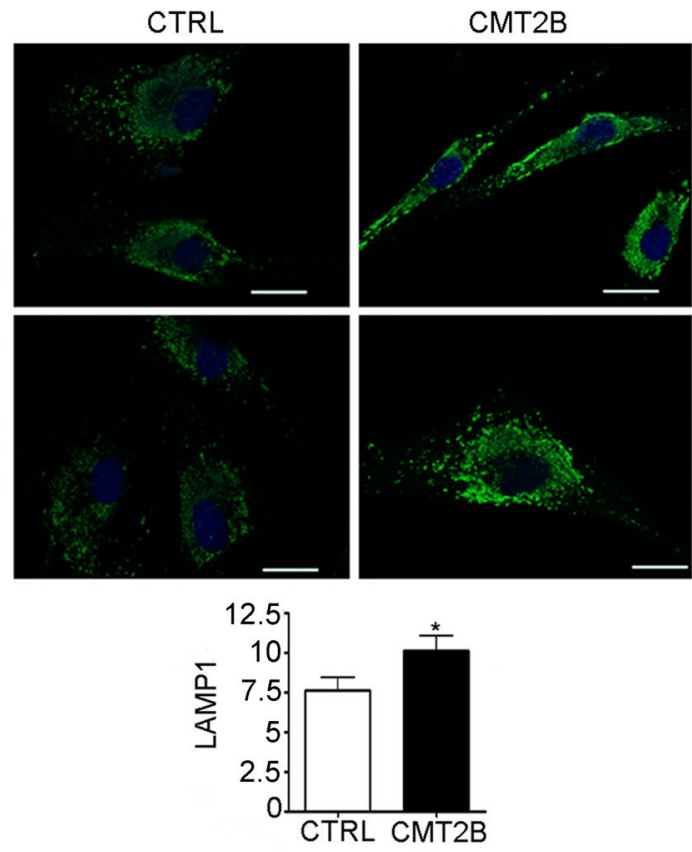

(b) CTRL CMT2B

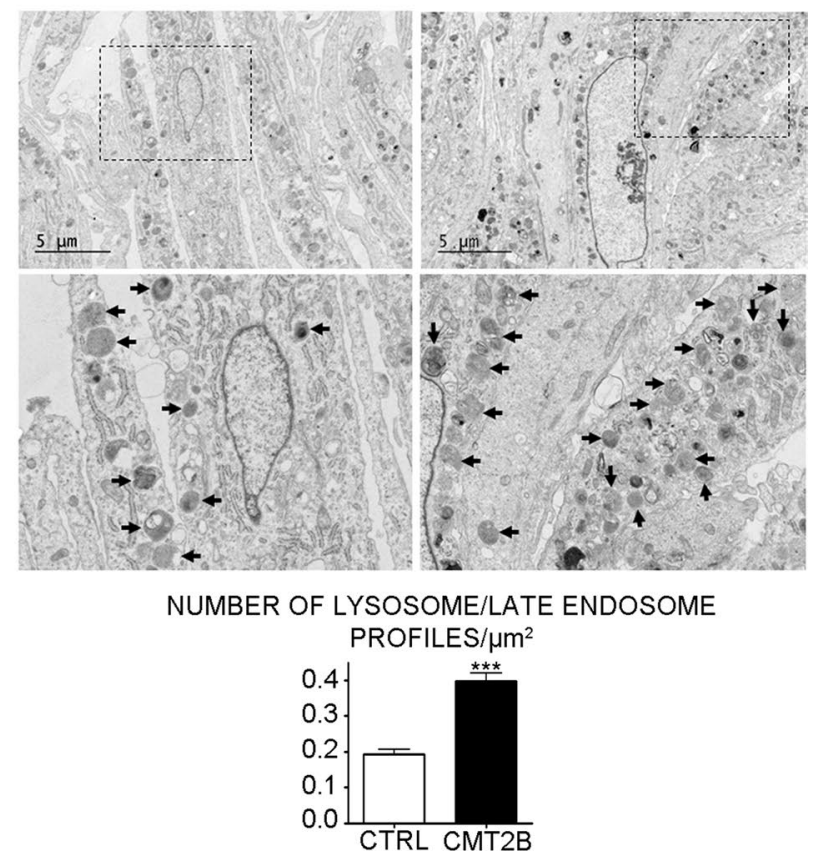

Fig. 2 Electron microscopy of control and CMT2B patient 1 fibroblasts. a Control and CMT2B fibroblasts from patient 1 carrying the $\mathrm{RAB} 7^{\mathrm{V} 162 \mathrm{M}}$ mutation were fixed and immunolabeled with antiLAMP1 followed by Alexa488-conjugated secondary antibody, while nuclei were stained with DAPI. Bars $20 \mu \mathrm{m}$. LAMP1 intensities of at least 50 cells per sample were measured using ImageJ. Graphs were generated with GraphPad. Mann-Whitney $U$ test was used for statistical analysis and control fibroblasts were selected as referring sample. ${ }^{*} p<0.05$. b The boxed areas are shown at higher magnification in the lower panels. Arrows indicate some of the lysosomes. Bars $5 \mu \mathrm{m}$. Graphs of lysosome number quantification were generated with GraphPad. Mann-Whitney $U$ test used for statistical analysis and control fibroblasts were selected as referring sample. $* * * p<0.001$ 
number of lysosome profiles in thin sections demonstrated that CMT2B cells have about twice as many lysosomes as compared to control cells (Fig. 2b), while no alterations in the formation of multivesicular bodies were observed (Fig. 3).

Altogether, these data indicate that CMT2B cells have more lysosomes.

\section{CMT2B fibroblasts show higher lysosomal activity}

The higher abundance of late endocytic proteins and of lysosomes in CMT2B cells prompted us to hypothesize a higher lysosomal activity in CMT2B fibroblasts. Cathepsin$\mathrm{D}$ is a lysosomal enzyme synthesized as an inactive precursor (pre-pro-cathepsin), converted into pro-cathepsin D $(52 \mathrm{kDa})$ in the endoplasmic reticulum and further processed into late endosomes and lysosomes into the 44-kDa form and then into the 32-kDa mature form [55-57]. Defects in cathepsin-D maturation correlate with alterations of lysosomal functions. Using a specific antibody able to detect the different immature and mature forms of cathepsin D, we could detect the immature forms both in control and CMT2B fibroblasts (Fig. 4a). Quantification of the ratio of immature cathepsin D on total cathepsin D indicates that cathepsin D processing is more efficient in CMT2B cells (Fig. 4a). In addition, quantitative analysis of the total amount of mature cathepsin D revealed that cathepsin D abundance in CMT2B fibroblasts was about twofold higher than in control cells (Fig. 4a). Treatment with cycloheximide, an inhibitor of protein synthesis, lowered this increase, suggesting that the higher amount of cathepsin D is due to increased protein synthesis (Fig. 4b).

Cathepsin D is important not only for lysosomal activity, but also for lysosome-mediated apoptosis [55]. T understand whether cathepsin D increase in CMT2B cells correlates with higher degradation activity, we performed a cathepsin $\mathrm{D}$ activity assay based on fluorescence release upon cleavage of a substrate. CMT2B fibroblasts showed higher fluorescence (Fig. 4c) and quantification revealed that cathepsin D activity in CMT2B cells was approximately $40 \%$ higher than in control fibroblasts (Fig. 4d).

To confirm increased lysosomal activity, we decided to test the enzymatic activity of other lysosomal proteins such as cathepsin- $\mathrm{L}$ and cathepsin-B using similar fluorescencebased assays on patient 1 fibroblasts. Both cathepsin $\mathrm{L}$ and cathepsin B activities were about $40 \%$ higher in CMT2B cells compared to control cells (Fig. 4e, f), thus confirming increased lysosomal activity. To establish whether the higher
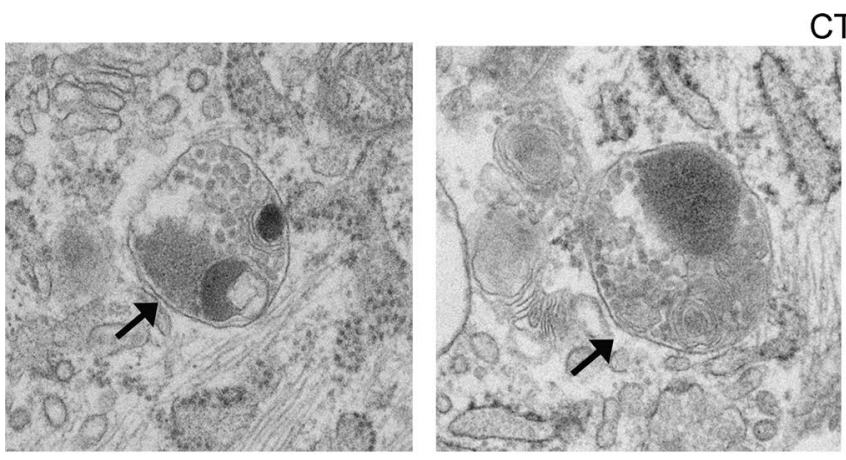

CTRL
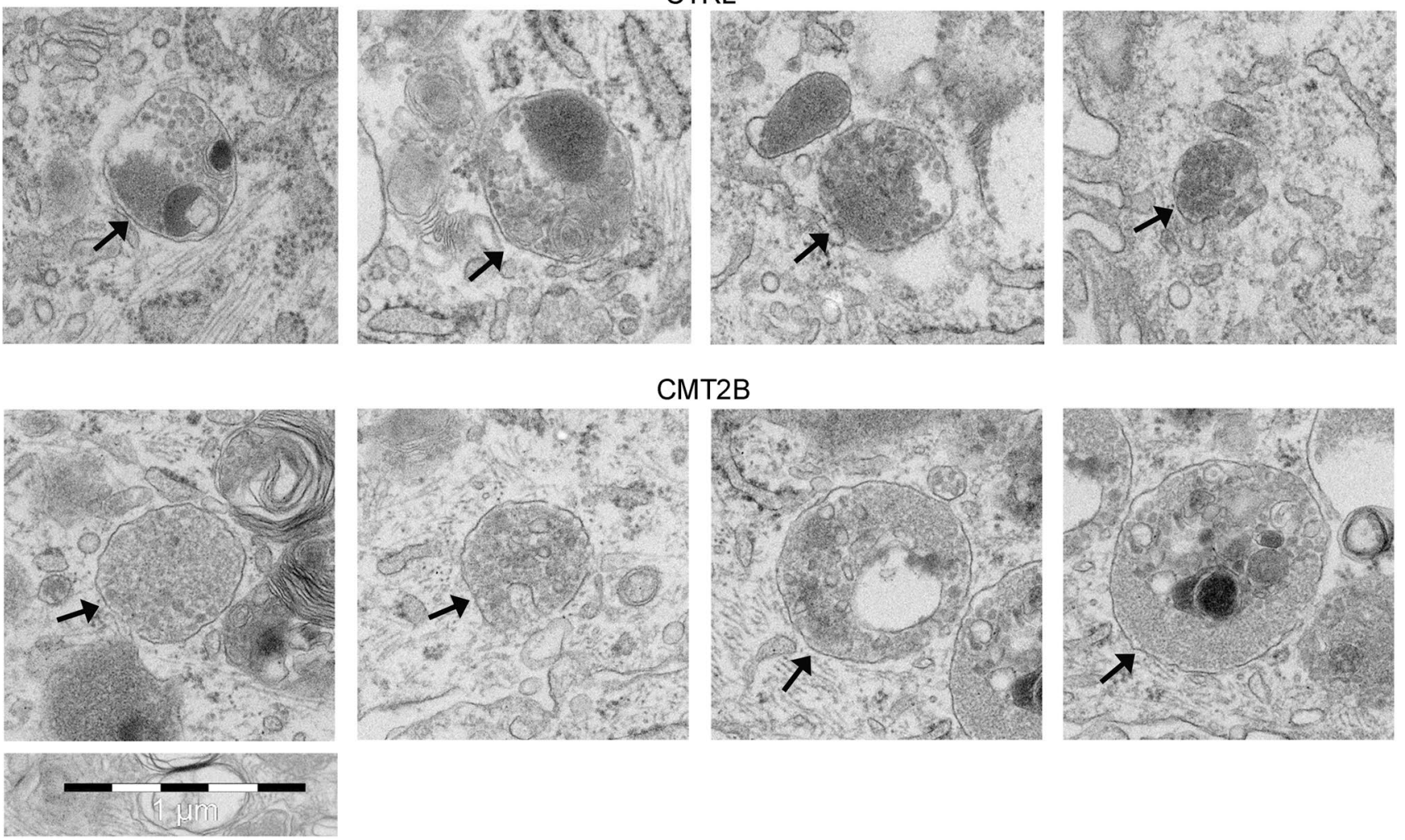

Fig. 3 Electron microscopy of multivesicular bodies from control and CMT2B patient 1 fibroblasts. Arrows indicate multivesicular bodies (MVBs) observed in control and CMT2B patient 1 carrying the RAB $7^{\mathrm{V} 162 \mathrm{M}}$ mutation. Bar $1 \mu \mathrm{m}$ 
(a)
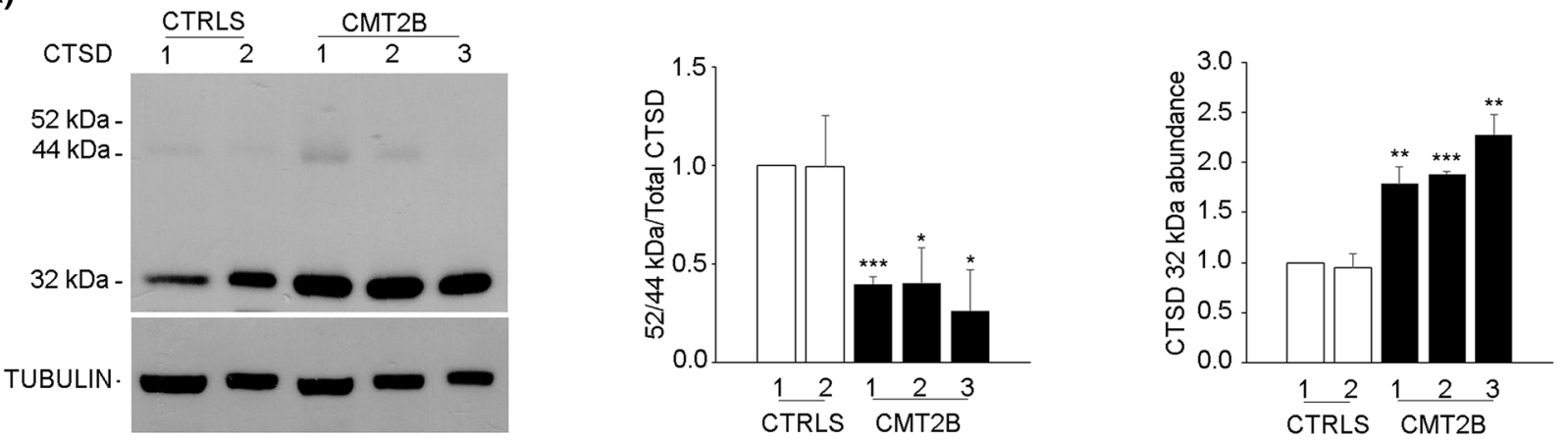

(b)
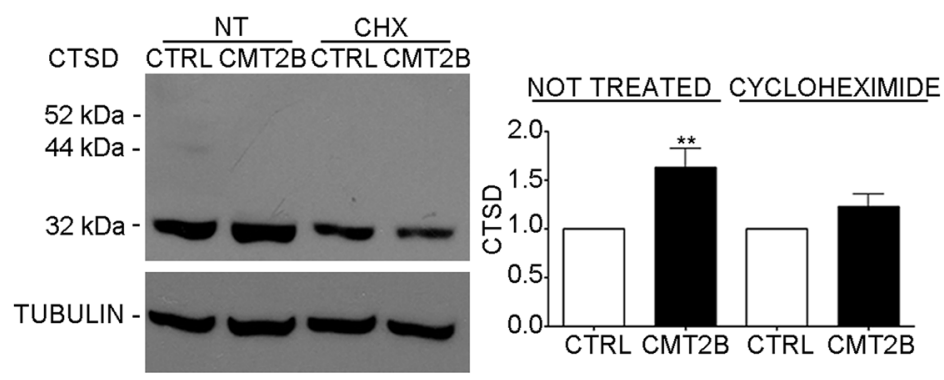

(c)

(d)

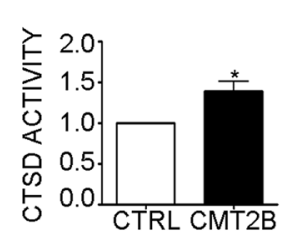

(e)

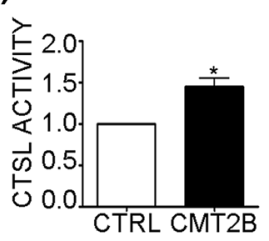

(f)

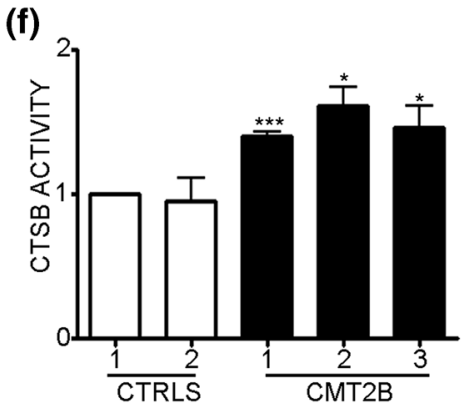

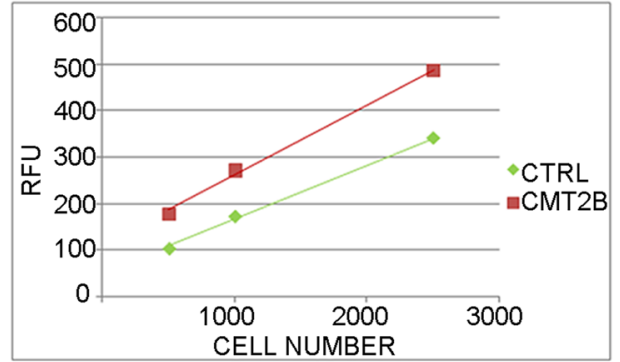

(g) (h)

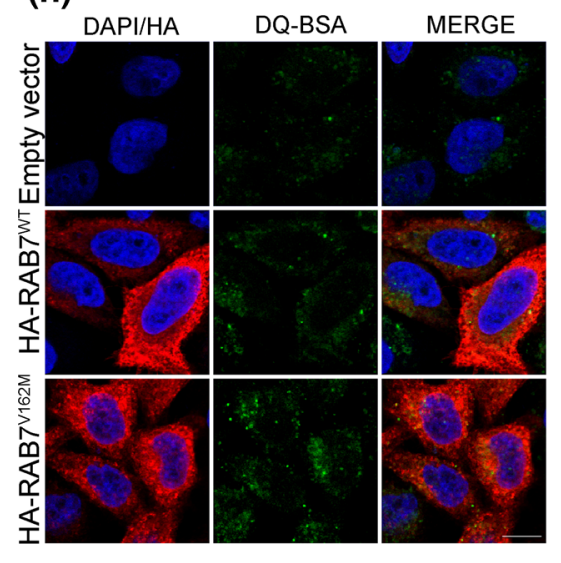

(i)

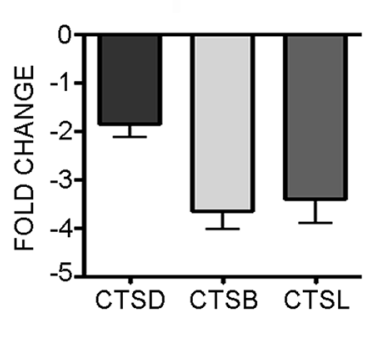


4Fig. 4 Lysosomal activity in CMT2B fibroblasts carrying the $\mathrm{RAB}^{\mathrm{V} 162 \mathrm{M}}$ mutation. a Lysates of two controls and CMT2B fibroblasts from three patients were subjected to immunoblotting using anti cathepsin D (CTSD) and anti-tubulin antibodies. Intensities of bands were measured by densitometry and normalized against tubulin. b Lysates of control and CMT2B fibroblasts from patient 1 untreated or treated with cycloheximide for $50 \mathrm{~h}$ were subjected to immunoblotting using anti cathepsin D and anti-tubulin antibodies. Intensities of bands were measured by densitometry and normalized against tubulin. c Different dilutions of control and CMT2B patient 1 lysates were tested for ability to cleave the MCA-labeled synthetic substrate. RFU per each dilution was evaluated after fluorimetric analysis. d Quantification of fluorescence data to evaluate cathepsin-D activity in control and CMT2B fibroblasts (patient 1). e The ability of cathepsin-L (CTSL) to cleave the substrate was evaluated in both control and CMT2B patient 1-derived fibroblasts. f Fibroblasts derived from two distinct control individuals and three CMT2B patients were analyzed to test cathepsin B (CTSB) activity. g The amount of cathepsin-D, L and B transcripts was quantified, compared to the GAPDH transcript as control, using real-time PCR, in control and CMT2B patients-derived fibroblasts. h HeLa cells were transfected for $24 \mathrm{~h}$ with the empty vector or plasmids encoding HA-tagged RAB7 $7^{\mathrm{WT}}$ or CMT2B-causing mutant RAB7 ${ }^{\mathrm{V} 162 \mathrm{M}}$. Cells were incubated for $6 \mathrm{~h}$ with DQ Green BSA and then processed for immunofluorescence analysis. Bar $10 \mu \mathrm{m}$. DQ BSA intensities were measured using ImageJ and Corrected Total Cell Fluorescence (CTCF) was calculated. Data represent the mean \pm SEM of at least 50 cells analyzed. Student's $t$ test was used for statistical analysis. Statistical comparisons of the samples are with RAB7 ${ }^{\mathrm{WT}}$. $* p<0.05$; $* * * p<0.001$. i Control and CMT2B fibroblasts from patient 1 were treated with DQ-BSA for $48 \mathrm{~h}$, then fixed and observed on a confocal microscope. Bars $20 \mu \mathrm{m}$. The intensities of manually determined areas for each single cell were measured using Image J. At least 50 cells per sample were analyzed. Graphs were generated with GraphPad. All data represent the mean \pm SEM of at least three independent experiments. Student's $t$ test or Mann-Whitney $U$ test (for DQ-BSA quantification) was used for statistical analysis and control fibroblasts were selected as referring sample. ${ }^{*} p<0.05 ;{ }^{* *} p<0.01$, ${ }^{* * *} p<0.001$

To further investigate lysosomal activity, we used the $\mathrm{DQ}^{\mathrm{TM}}$ BSA assay in which cells are incubated with the self-quenched $\mathrm{DQ}^{\mathrm{TM}} \mathrm{BSA}$, whose cleavage by proteases in an acidic compartment generates a highly fluorescent product. HeLa cells transfected with the empty vector or with a construct encoding HA-tagged RAB $7^{\text {WT }}$ or the CMT2Bcausing mutant RAB $7^{\mathrm{V} 162 \mathrm{M}}$ were incubated with DQ-BSA. After $6 \mathrm{~h}$ of incubation with DQ ${ }^{\mathrm{TM}}$ Green BSA, HeLa cells expressing CMT2B-causing mutant RAB $7^{\mathrm{V} 162 \mathrm{M}}$ showed higher fluorescence compared to cells transfected with empty vector and plasmid encoding HA-tagged RAB ${ }^{\text {WT }}$ (Fig. 4h). Similarly, control fibroblasts and CMT2B fibroblasts from patient 1 were analyzed after $48 \mathrm{~h}$ of incubation with $\mathrm{DQ}^{\mathrm{TM}}$ Red BSA. Control fibroblasts displayed a lower level of fluorescence compared to CMT2B fibroblasts and quantification revealed an approximately twofold increase of fluorescence in CMT2B compared to control cells $(p<0.0001)$ (Fig. 4i).

Altogether, these data demonstrate that lysosomal activity in CMT2B cells is higher than in control cells and that this is caused by the expression of the $\mathrm{RAB} 7^{\mathrm{V} 162 \mathrm{M}}$ mutant protein.

\section{EGFR degradation is higher in CMT2B cells}

The higher expression of late endocytic proteins, the lower abundance of sorting regulators and the increased number of lysosomes and lysosomal activity suggest alterations of the degradative pathway in CMT2B fibroblasts. RAB7 regulates trafficking and degradation of EGFR and previous data on EGFR degradation obtained on cells transiently or stably transfected with the CMT2B-causing RAB7 mutant proteins produced conflicting results. In fact, transient expression of CMT2B-causing RAB7 mutant proteins in HeLa cells caused normal or increased EGFR degradation [35, $36]$, while in Hela and PC12 stable cell lines expressing these mutant proteins inhibition of EGFR degradation was reported [58].

To solve this issue and establish if also EGFR degradation is affected in CMT2B cells, we measured EGFR degradation in CMT2B fibroblasts carrying the RAB $7^{\mathrm{V} 162 \mathrm{M}}$ mutation (Fig. 5a). Control and CMT2B cells were able to degrade EGFR efficiently but, notably, CMT2B fibroblasts showed a higher degradation activity at $360 \mathrm{~min}$. In fact, quantification of EGFR degradation at $360 \mathrm{~min}$ in CMT2B patient 1 and patient 2 was significantly higher than controls, while in patient 3 was higher but not statistically significant (Fig. 5b). EGFR degradation assay at different time points on control and patient 1 fibroblasts revealed increased degradation both at time point 180 and $360 \mathrm{~min}$ (Fig. 5c). Our results are in agreement with previous data obtained on transiently transfected HeLa cells, but also with data on transferrin receptor degradation that was increased in fibroblasts from CMT2B patient $1[35,36,43]$.

To evaluate if higher degradation is due to increased trafficking speed, we performed an EGF internalization assay and measured colocalization between internalized Rhodamine-EGF and LAMP1 at different time points. Interestingly, we found that in patients' fibroblasts rhodamine-EGF and LAMP1 colocalization is higher at $1 \mathrm{~h}$ and $2 \mathrm{~h}$ compared to controls indicating that trafficking to late endosomes and lysosomes is faster in CMT2B fibroblasts compared to control cells (Fig. 5d).

These results, together with quantitative analysis of late endocytic proteins, strongly indicate that the endocytic degradative pathway is increased in CMT2B fibroblasts.

\section{EGFR signaling and cell migration are altered in CMT2B fibroblasts}

The activation of EGFR stimulates a number of signaling pathways, among which are phosphatidylinositol 3 kinase (PI3K/AKT) and Ras-mitogen-activated protein kinase (MAPK) pathways, to promote cell survival and proliferation [59]. To identify downstream factors of EGFR affected in CMT2B, we analyzed the abundance and activation of 
(a)

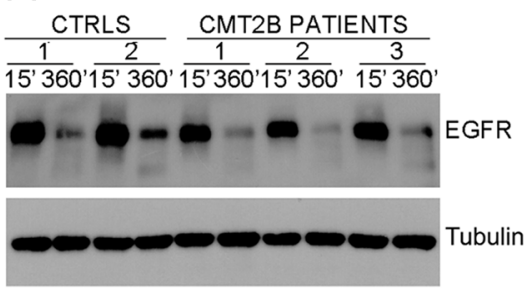

(d)

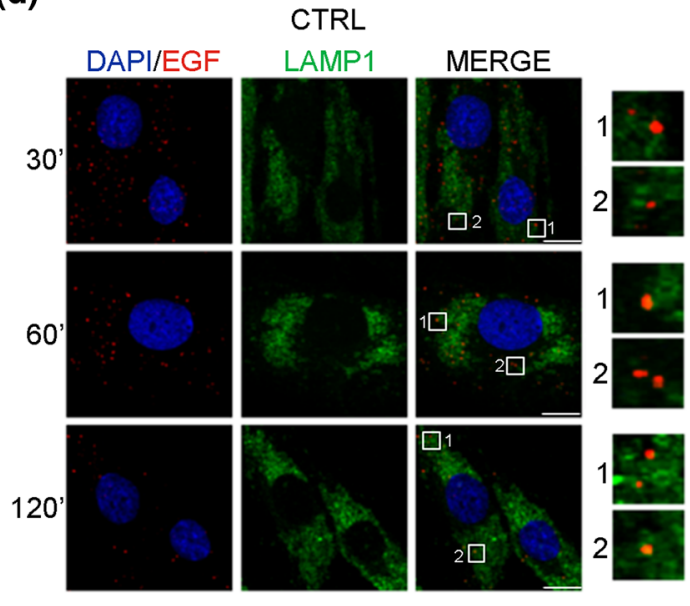

(b)

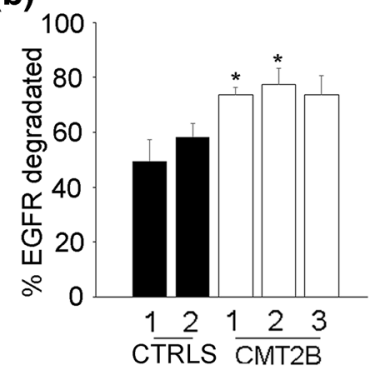

(c)

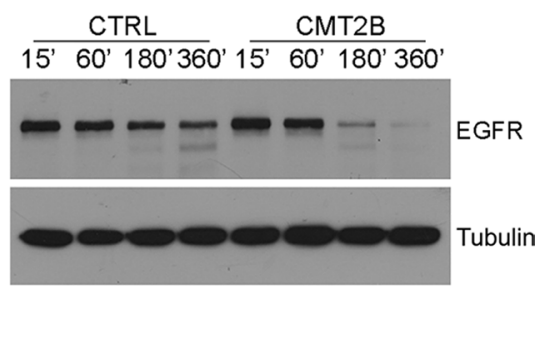

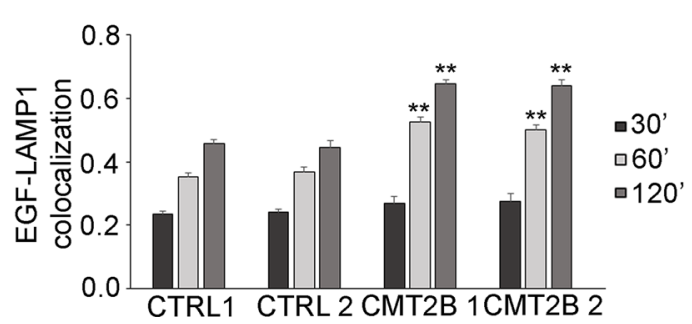

CMT2B

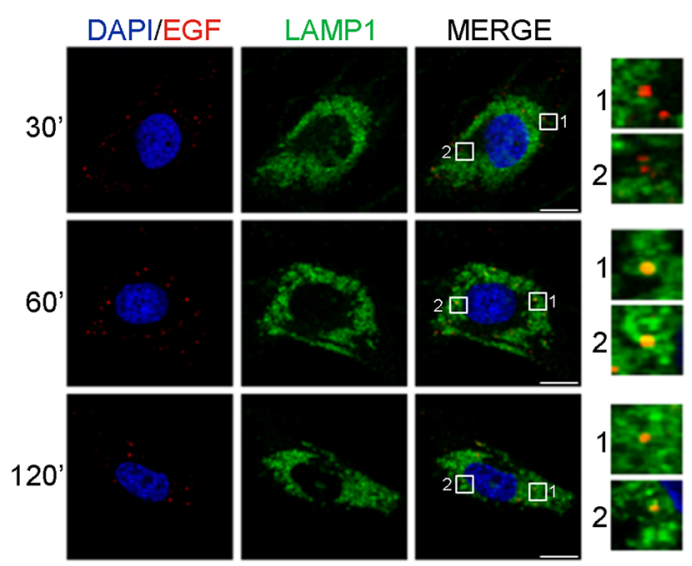

$60^{\prime}$

$120^{\prime}$

Fig. 5 Degradation activity is higher in CMT2B fibroblasts carrying the $\mathrm{RAB} 7^{\mathrm{V} 162 \mathrm{M}}$ mutation. a Fibroblasts derived from two healthy individuals and three CMT2B patients were incubated with cycloheximide for $1 \mathrm{~h}$ and subsequently stimulated with EGF for 15 and $360 \mathrm{~min}$. Cell lysates were analyzed by immunoblotting with antibody against EGFR and tubulin. b Densitometric analysis was performed with NIH ImageJ normalizing against tubulin. Statistical analysis was performed using Student's $t$ test with control fibroblasts as referring sample. c Fibroblasts derived from control and CMT2B (patient 1) were incubated with cycloheximide for $1 \mathrm{~h}$ and subsequently stimulated with EGF for the indicated times. Cell lysates were analyzed by immunoblotting with antibody against EGFR and

AKT and ERK proteins in fibroblasts derived from three CMT2B patients and from two healthy individuals. Consistently with increased degradation of EGFR, we observed in CMT2B fibroblasts from the three patients a significant reduction in the activation of both AKT and ERK (Fig. 6a).

EGFR is also important for the regulation of cell motility $[19,49]$. As we demonstrated that the RAB7 $7^{\mathrm{V} 162 \mathrm{M}}$ mutation affects EGFR degradation and, as a consequence, inhibits AKT and ERK signaling, we hypothesized tubulin. d Skin fibroblasts derived from two healthy individuals and two CMT2B patients (patients 1 and 2) were incubated overnight in starvation medium and then incubated for $1 \mathrm{~h}$ at $4{ }^{\circ} \mathrm{C}$ with rhodamine-EGF. After several washing, cells were incubated in complete DMEM medium at $37{ }^{\circ} \mathrm{C}$ for $30 \mathrm{~min}, 1 \mathrm{~h}$ and $2 \mathrm{~h}$ and then fixed, permeabilized, immunolabeled with anti-LAMP1 followed by Alexa488conjugated secondary antibody while nuclei were stained with DAPI. For each image, magnifications of the boxed areas are shown. Bars $10 \mu \mathrm{M}$. Data represent the mean \pm SEM of at least 50 cells of three independent experiments. Statistical analyses were performed using Student's $t$ test with control fibroblasts as referring sample. ${ }^{* *} p<0.01$

inhibition of cell migration. To measure cell migration, we performed a wound-healing assay. Control and CMT2B fibroblasts were grown to confluence, the cell layer was scratched and the wound area was monitored at different time intervals. Interestingly, we observed an approximately twofold increase in cell migration for CMT2B fibroblasts compared to control cells at $15 \mathrm{~h}$ after the scratch (Fig. 6b). Given this unexpected result, we investigated other players in cell migration. 
RAC1, a Ras-related small GTPase involved in several cellular pathways, is a member of the RHO family that regulates actin cytoskeleton during cell motility [60]. In addition, during cell migration, RAC1 activity is regulated by RAB7 [61]. Therefore, we analyzed the abundance and activation of RAC1 in CMT2B fibroblasts. We did not detect any differences in RAC1 protein amount between the control and CMT2B cells (Fig. 6c). However, we observed a significant increase of GTP-bound active RAC1 in CMT2B cells compared to controls, demonstrating that in these cells RAC1 is more activated (Fig. 6c).

Matrix metalloproteinases (MMPs) comprise a family of endopeptidases that degrade extracellular proteins promoting cell migration [62] and RAC1 is a mediator of MMP-2 activation [63]. Therefore, we monitored MMPs activity by gelatin zymography in control and CMT2B fibroblasts. In the medium of CMT2B cells, we detected two bands with different intensity corresponding to inactive and active MMP-2 (Fig. 6d) while in control cells only the inactive band was present.

To investigate the mechanism leading to increased RAC1 activation in CMT2B patients, we evaluated the expression of ARHGEF6 and RACGAP1 $[64,65]$. We did not observe any difference in RACGAP1 expression between control and CMT2B fibroblasts, while we found an increased expression of ARHGEF6 in CMT2B fibroblasts (Fig. 6e) that could explain the increased $\mathrm{RAC} 1$ activation in these cells.

Altogether, these data demonstrate that EGFR signaling and cell migration are affected in CMT2B fibroblasts.

\section{CMT2B sensory neurons show higher lysosomal activity}

To confirm the data obtained in fibroblasts we decided to evaluate the abundance of lysosomal markers and lysosomal functionality in iPSC-derived sensory neurons from two CMT2B patients carrying the RAB $7^{\mathrm{V} 162 \mathrm{M}}$ mutation compared to two healthy individuals. The iPS cells obtained from CMT2B patients and controls showed the expression of the expected markers of undifferentiated ES cells (Fig. $7 \mathrm{a}-\mathrm{c}$ ), as well as pluripotent differentiation capacity into the three germ layers in vitro and in vivo (Fig. 7d, Supplemental Fig. 1).

iPSC-derived sensory neurons were grown on Matrigelcoated coverslips and showed normal axon network formation and expected markers of sensory dorsal root ganglia neurons (Fig. 8a). Previous data indicated that expression of CMT2B-causing RAB7 mutant proteins caused inhibition of neurite outgrowth [40, 41]. To assess neurite outgrowth in iPSCs-derived sensory neurons from control and CMT2B patients, the young neurons were plated and analyzed using IncuCyte ${ }^{\circledR}$ S3 Live-Cell Analysis System for 6 days. Interestingly, CMT2B neurons showed reduced neurite extensions as compared to controls (Fig. 8b), confirming previous results obtained by transient expression of RAB7 mutant proteins.

When we investigated in these cells late endosomal and lysosomal markers, we found that CMT2B neurons showed a twofold higher expression of LAMP1, confirming previous data obtained on CMT2B skin fibroblasts (Fig. 9a). We then performed immunofluorescence analysis to evaluate distribution and abundance of LAMP1-positive organelles and we observed a similar distribution in the perinuclear region of LAMP1 in the control and CMT2B neurons. However, CMT2B neurons showed a stronger expression of LAMP1 that was quantified confirming the data obtained by Western blotting and indicating an increase of about two times (Fig. 9b). We next investigated the abundance of the mature form of cathepsin D and we found an increase in CMT2B patients, similar to what we observed in fibroblasts (Fig. 9c). As higher cathepsin D maturation correlates with higher lysosomal activity, we performed a DQ-Red BSA assay. As expected, CMT2B neurons display higher fluorescent DQBSA staining than control neurons indicating higher lysosomal activity. Quantification of DQ-Green BSA puncta revealed an increase of about fivefold (Fig. 9d).

Altogether, these results indicate that iPS-derived neurons from CMT2B patient show higher lysosomal activity.

\section{Discussion}

In this study, we demonstrate that late endocytic traffic is altered in CMT2B compared to control cells. In particular, we show that RAB9 and CI-MPR as well as lysosomal proteins such as LAMP1, LAMP2 and cathepsin D are more abundant in these cells and that lysosomes, more numerous in CMT2B cells compared to control, display increased activity (Fig. 10). Indeed, the activity of three lysosomal enzymes (cathepsin B, D and L) is increased as well as degradation of EGFR and DQ BSA (Fig. 10). These data are consistent with several studies demonstrating that alterations of endocytic traffic induce neurodegeneration $[11,66]$. In fact, upregulation of RAB proteins involved in endocytic traffic occurs during the progression of a number of neurodegenerative disorders including Alzheimer's disease [67-70]. Furthermore, increased transport to endosomes of proteases, such as cathepsin B and L, coupled with higher expression of CI-MPR, was shown in Alzheimer's disease $[68,71]$. Indeed, in neurodegenerative disorders, increased endocytic flux induces abnormal degradation of signaling complexes, impairing neurotrophin receptor signaling that, in turn, could be responsible for neurodegeneration.

We also found that, although the expression of early endocytic RABs is not altered in CMT2B cells, EAP30 (ESCRTII member) and TSG101 (ESCRT-I member) levels were 
(a) $\frac{\text { CTRLS }}{12} \frac{\text { CMT2B }}{123}$
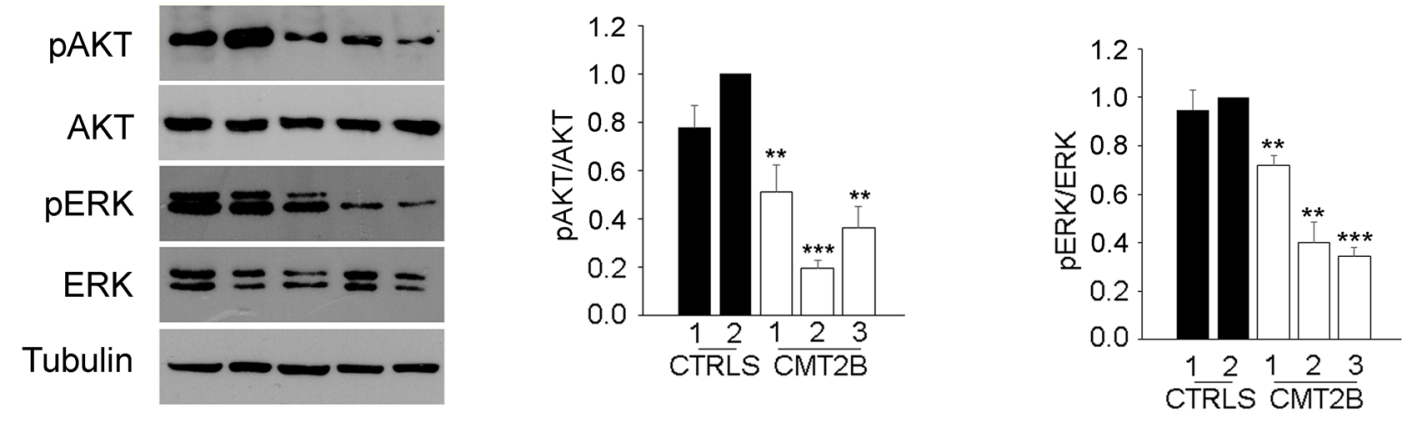

(b)

TO

T15h

T24h
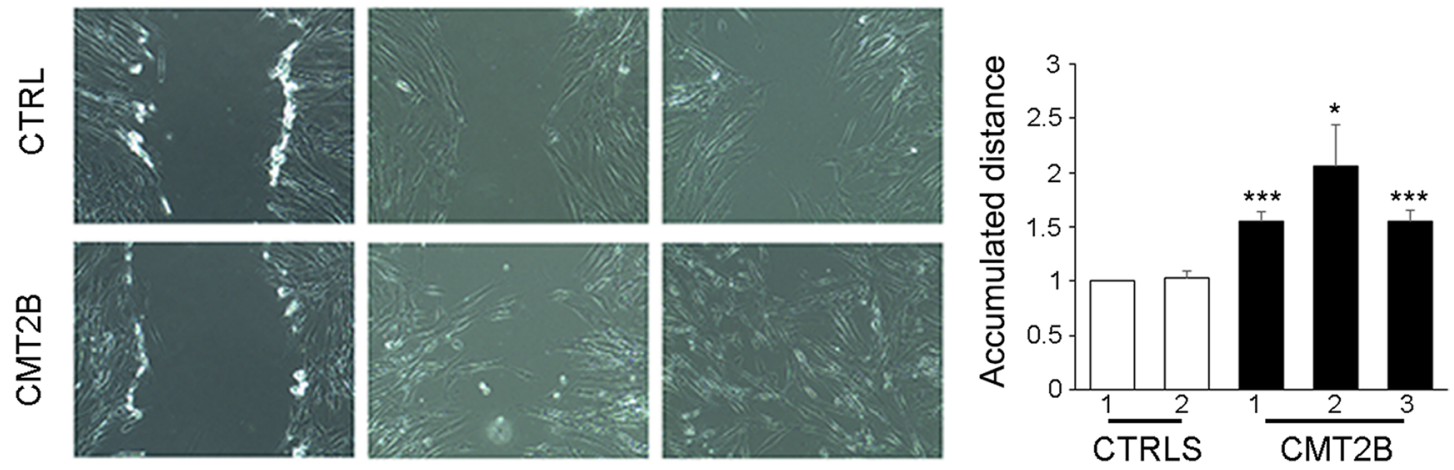

(c)
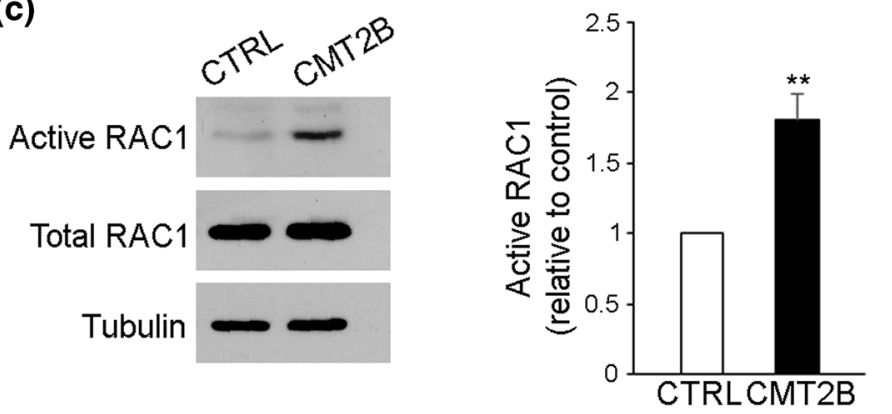

(d)

(e)

\section{$\frac{\text { CTRLS }}{12} \frac{\text { CMT2B }}{123}$}
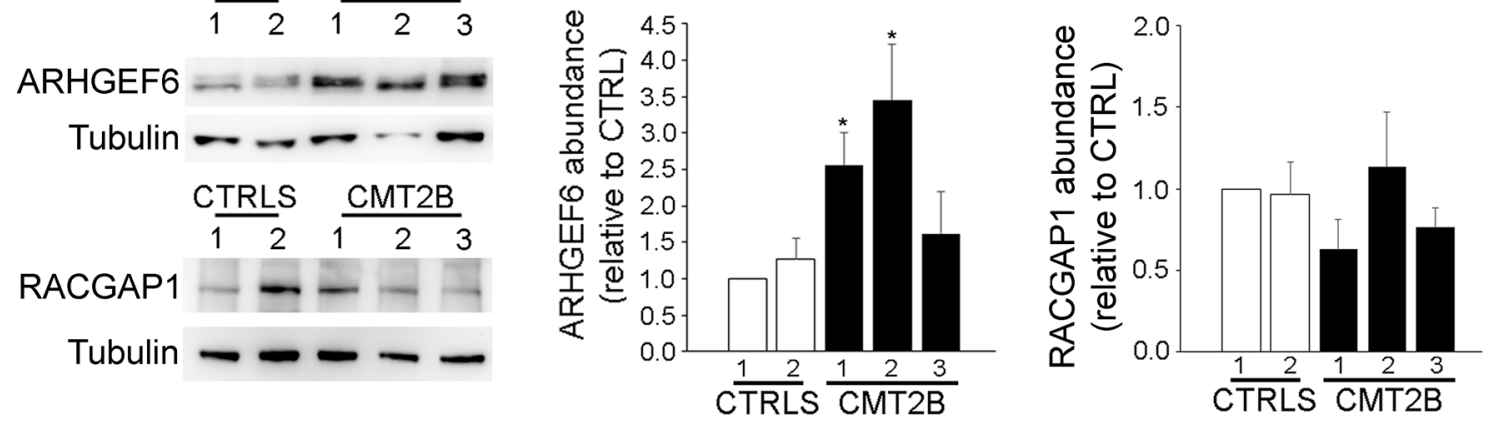

strongly reduced (Fig. 10). The reduction of ESCRT components in CMT2B cells is consistent with previously reported cargo-dependent degradation of ESCRT components [72-74]. Indeed, it was shown that ESCRT-I components are delivered together with the cargo to lysosomes, where they are degraded [74]. Thus, lower levels of TSG101 are indicative of increased utilization. Therefore, our data on increased lysosomal activity and increased EGFR degradation are in 
4Fig. 6 Rac1 activity and cell migration are altered in CMT2B fibroblasts carrying the RAB $7^{\mathrm{V} 162 \mathrm{M}}$ mutation. a Lysates of two controls and three CMT2B fibroblasts were analyzed by immunoblotting using anti-AKT, anti-pAKT, anti-ERK and anti-pERK. Bands were quantified using NIH ImageJ and normalized against total protein. All data represent the mean \pm SEM of at least three experiments. Statistical analysis was performed using Student's $t$ test with control fibroblasts as referring sample. ${ }^{*} p<0.05,{ }^{*} p<0.01$, $* * * p<0.001$. b Fibroblasts from control and CMT2B patients were imaged during wound healing assay. Images of initial time point (T0), $15 \mathrm{~h}$ and $24 \mathrm{~h}$ after the scratch are shown. Accumulated distance, the total distance that the cell traveled in a certain amount of time, is shown. Data represent the mean \pm SEM of four experiments. Statistical analysis was performed using Student's $t$ test with control fibroblasts as referring sample. $* p<0.05$; *** $p<0.001$. c Lysates of control and CMT2B fibroblasts (patient 1 ) were subjected to RAC1 activation assay and then subjected to western blot analysis using anti-RAC1 and anti-tubulin antibody. Quantification of active RAC1 in control and CMT2B cells is shown. Data represent the mean \pm SEM of at least three experiments. $* * p<0.01$. d Gelatin zymography was performed using conditioned medium of fibroblasts derived from a healthy individual and three CMT2B patients. Representative results are shown. e Lysates of two controls and three CMT2B skin fibroblasts were analyzed by immunoblotting using anti-ARHGEF6 and anti-RACGAP1 antibodies. Bands were quantified using NIH ImageJ and normalized against tubulin. All data represent the mean \pm SEM of at least three experiments. Statistical analysis was performed using Student's $t$ test with control fibroblasts as referring sample. $* p<0.05$

agreement with lower abundance of ESCRT proteins. Furthermore, it has been demonstrated that one of the RAB7 mutant causing CMT2B, the RAB7 ${ }^{\mathrm{K} 157 \mathrm{~N}}$, interacts weakly with a subunit of the retromer complex that controls endosome-to-Golgi retrieval of CI-MPR receptor, thus reducing the efficiency of endosomal protein sorting [75]. Therefore, increased expression of CI-MPR in CMT2B cells could be due to a compensatory mechanism to counteract the presence of the $\mathrm{RAB} 7^{\mathrm{V} 162 \mathrm{M}}$ mutant protein.

We observed increased degradative activity in CMT2B cells. Our data are in agreement with previous findings demonstrating that CMT2B-causing RAB7 mutants show increased interaction with ORP1L (cholesterol sensor oxysterol-binding protein-related protein 1L), and RILP (Rabinteracting lysosomal protein), two RAB7 effector proteins controlling transport of endosomes from the periphery of the cell toward the MTOC (MicroTubule Organizing Center) during endosome maturation [34]. Accordingly, it was shown that the expression of CMT2B-causing mutants restores EGFR degradation that was inhibited after RAB7 silencing [35, 36]. Moreover, higher lysosomal activity and increased degradation of EGFR in CMT2B cells suggest increased degradation also of other signaling receptors and consequent inhibition of signaling. Notably, expression of RAB7 mutant proteins affects the axonal transport by modifying trafficking and signaling of NGF (nerve growth factor) and its receptor, TrkA [76]. Importantly, it was also demonstrated that CMT2B-causing RAB7 mutants cause a reduction of TrkA surface level, which was hypothesized to be the consequence of premature degradation of TrkA induced by lysosomal activity [76]. In fact, hyperactivation of degradation within axons could induce a premature termination of TrkA signaling, with consequent inhibition of retrograde signaling, possibly contributing to axonal degeneration [76]. Finally, it was reported that increased endocytic flux in neurons induces neurodegeneration in Alzheimer's disease, as a consequence of reduced neurotrophin receptors expression and signaling, [67, 69]. Thus, we hypothesize that the increased lysosomal activity could affect signaling because of premature degradation of signaling receptors, thus contributing to the axonal degeneration occurring in CMT2B disease.

We also observed an increased migration of CMT2B fibroblasts, though EGFR degradation was higher in these cells. These results may appear contradictory, as it was shown that the downstream signaling pathways of numerous receptor tyrosine kinases, including EGFR, are involved in the regulation of cell motility [77, 78]. Indeed, extracellularregulated kinase (ERK), Jun kinase and tumor protein (p)38 affect various cell functions, including migration [79]. Also phosphatidylinositol-3 kinase (PI3K) controls cell motility through the activation of protein kinase B (Akt) and other targets [80, 81]. However, cell migration does not exclusively depend on EGFR signaling. In fact, it was demonstrated that inhibition of EGFR activation in tumor cells leads to activation of a $\beta 1$ integrin pathway that promotes migration, undermining EGFR blockade [82]. Furthermore, there are many mechanisms that promote migration independently of Akt, and one of the most important is the remodeling of the actin cytoskeleton mediated by RAC1 [83, 84]. In fact, it was found that $\beta 1$ integrins locally activate RAC1 [85]. In CMT2B cells, we found an increased RAC1 activation, while we did not detect any difference in RAC1 total protein amount. Therefore, our data are in agreement with previous findings showing the existence of alternative pathways that regulate cell motility. Furthermore, it was previously reported that $\mathrm{RAC} 1$ promotes MMP-2 activation [63] and we observed higher activation of this gelatinase in CMT2B patients. Thus, a decrease in EGFR signaling due to its higher degradation could trigger $\beta 1$ integrin pathway that leads to RAC1 and MMP-2 activation, causing increased migration of CMT2B cells in an EGFR-independent manner.

We previously found that the expression of CMT2Bcausing RAB7 mutants negatively affects the role of RAB7 in autophagy [43]; in particular, in CMT2B fibroblasts we observed a reduced localization of RAB7 on autophagosomes after autophagy induction, a decreased number of LC3B-positive vesicles and a reduced autophagic flux, demonstrated by bafilomycin $A_{1}$ treatment [43]. We also established that the expression of the RAB7 ${ }^{\mathrm{V} 162 \mathrm{M}}$ does not affect autophagosomal biogenesis, but it only alters later phases of autophagosome maturation [43]. Considering 
(a)
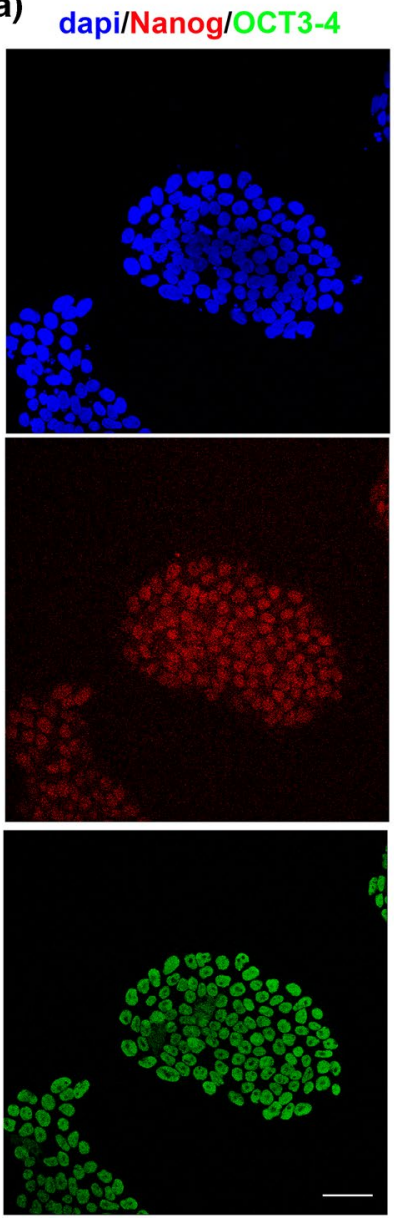

(b)

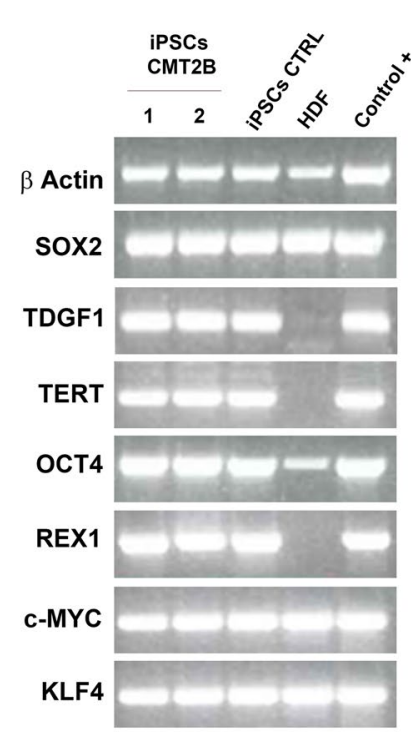

(c)
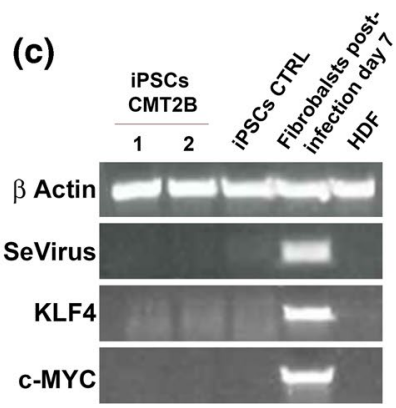

(d)
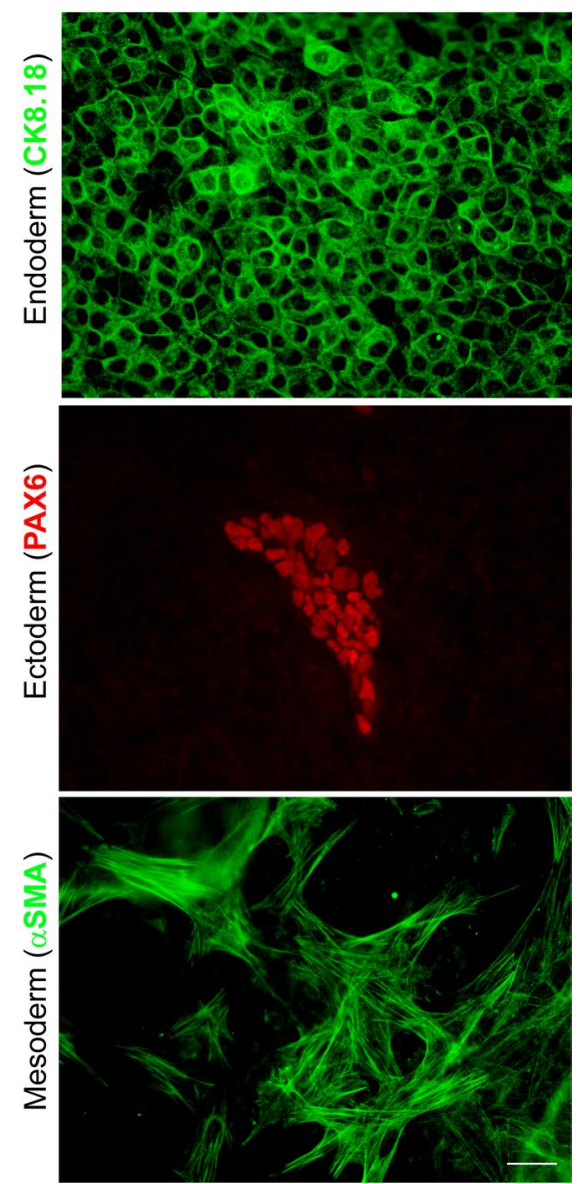

Fig. 7 Expression of human embryonic stem cell markers and pluripotency of control and CMT2B hiPS cells. a Immunohistochemistry for embryonic stem (ES) cell markers of CMT2B iPS cells. Bars $50 \mu \mathrm{m}$. b RT-PCR analysis of ES cell-marker genes in human iPS cells, human dermal fibroblast (HDF) and previously derived iPS cell as positive control. Primers used for Oct3/4, Sox2, Klf4, and c-Myc specifically detect the transcripts from the endogenous genes, but not from the retroviral transgenes. $\mathbf{c}$ RT-PCR for expression of retroviral transgenes in human iPS cells, HDF, and HDF 7 days after the transduction with the four retroviruses as a positive control. d Immunohistochemistry of iPS cells spontaneously differentiated show markers for the three germ layers. Bars $50 \mu \mathrm{m}$ that RAB7 controls fusion of autophagic vacuoles with late endosomes and lysosomes, the present data, showing increased expression of lysosomal membrane proteins and enzymes and increased lysosomal activity, seem to be in contrast. However, it was reported that thapsigargin distinguishes membrane fusion in the late stages of the two pathways, endocytosis and autophagy, indicating that the two pathways, although sharing many components of the membrane traffic machinery, can be independently regulated [86, 87]. In addition, CMT2B mutations do not generate classical gain or loss of function RAB7 mutants. It was reported that RAB7 mutants would cause the disease due to the misregulation of native RAB7 activity [34]. Indeed, these mutant proteins display a higher nucleotide $K_{\text {off }}$ and thus they tend to release nucleotides (both GTP and GDP) earlier as compared to the wt protein [34-36]. The $k_{\text {off }}$ is higher for GDP than for GTP and, considering that GTP concentration in the cell is approximately one order of magnitude higher than GDP, these mutants are mainly in the GTP-bound form, as each time that they release GDP prematurely they have a higher probability to bind GTP. However, due to the increased $K_{\text {off }}$ for GTP compared to the wt protein, they also tend to release GTP prematurely and this affects negatively the GTPase activity per binding event [34-36]. Thus, these mutant proteins are dysfunctional, as they have unregulated nucleotide exchange and activation [34]. They can stimulate a process as they are GTP bound but, at the same time, if the reaction controlled by RAB7 requires being stimulated by RAB7-GTP for a certain amount of time, premature release of GTP could block the controlled process. Hence, depending on the kinetic requirements of the regulated process, these mutant proteins could behave as active or inhibitory mutants. These considerations may explain the apparently conflicting data present in the literature. Indeed, 

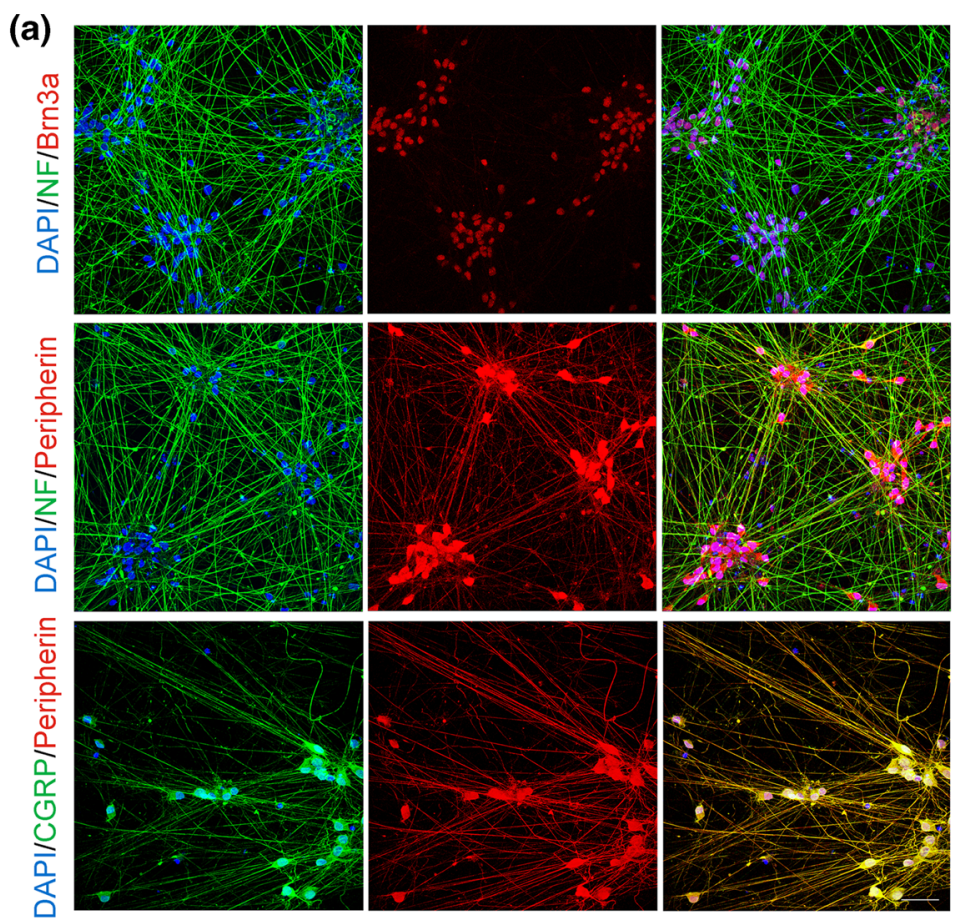

(b)

CTRL

CMT2B 2
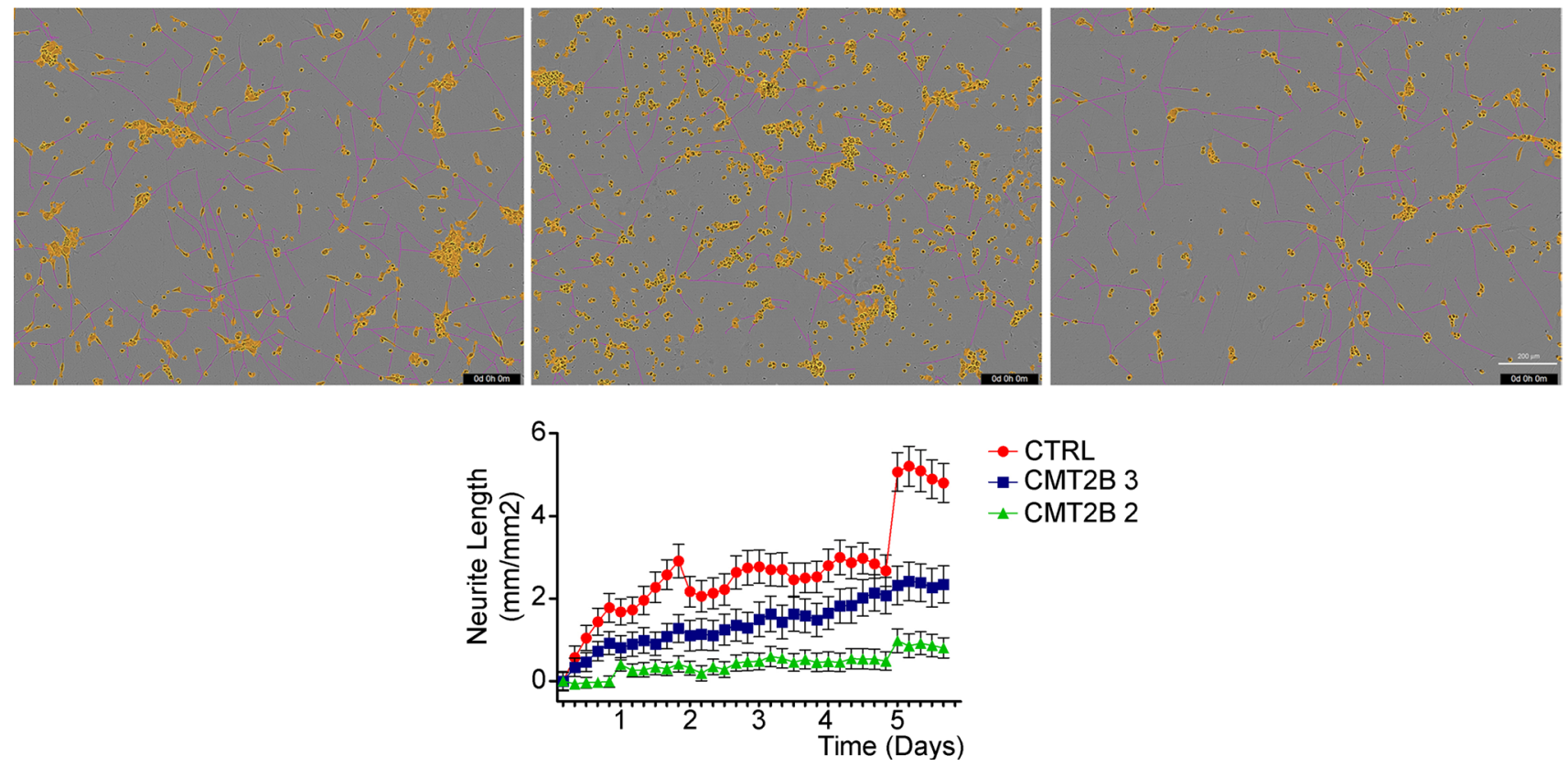

- CTRL

- - CMT2B 3

$\triangle \mathrm{CMT2B} 2$

Fig. 8 CMT2B peripheral sensory neurons show inhibited neurite outgrowth. a Control iPS cells were differentiated in peripheral sensory neurons and analyzed by immunohistochemistry at 17 days of differentiation for Brn3a, Neurofilaments, Peripherin and CGRP. Bars $50 \mu \mathrm{m}$. b Phase contrast images of iPSCs-derived sensory neurons from control (CTRL) and CMT2B patients carrying the RAB $7^{\mathrm{V} 162 \mathrm{M}}$ mutation (\#2 and \#3) 6 days after plating. The IncuCyte automated

for instance, in the Drosophila model of the disease, it was established that neurodegeneration was due to a partial loss of function of RAB7, while studies on zebrafish showed that acquisition and analysis show the extension of neurites growth (pink). Neuron cell body clusters are marked in yellow. Bar $200 \mu \mathrm{m}$. Automated quantification of neurite length for a time window of 6 days after plating. Neurite length data were collected in units of $\mathrm{mm}$ of total neurites detected $/ \mathrm{mm}^{2}$ and all data are expressed relative to the respective day 0 of plating. Each group is represented by as mean $\pm \operatorname{SEM}(n=32$ image $)$

CMT2B-causing RAB7 mutations induce defects in axon growth, similarly to the constitutively active form of RAB7, thus suggesting that defects observed in the neuropathy are 
(a)

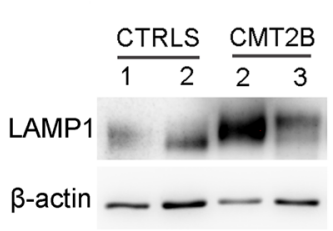

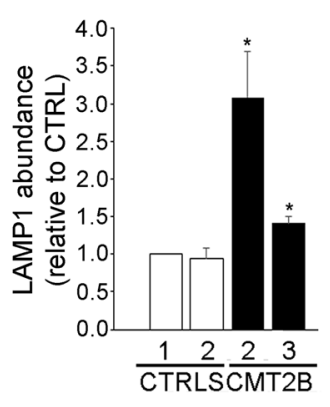

(c)

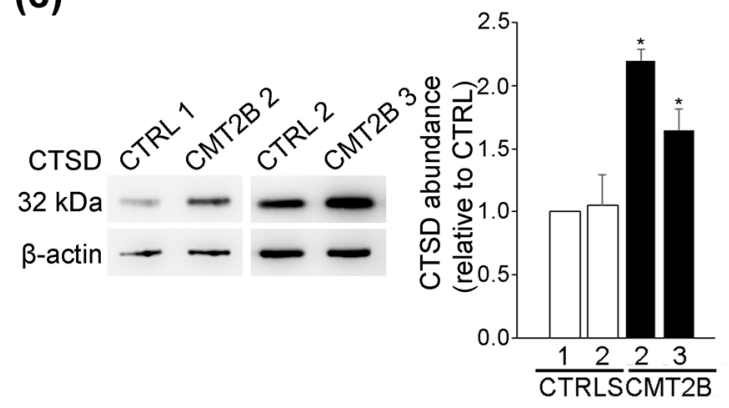

(b)

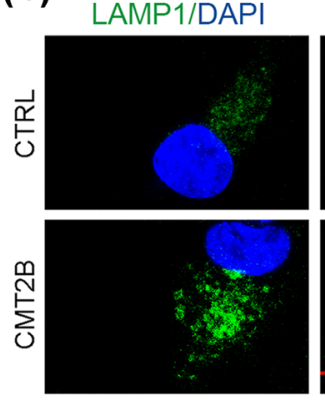

Peripherin

LAMP1/DAPI
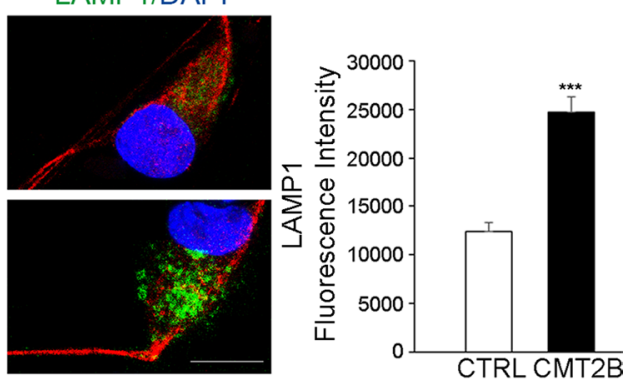

(d)

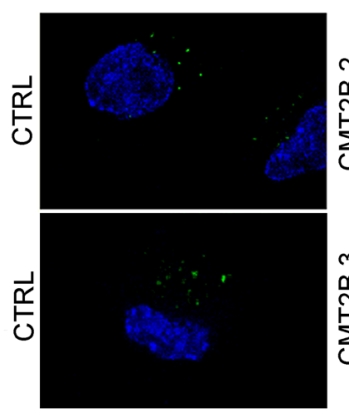

DQ-BSA/DAPI

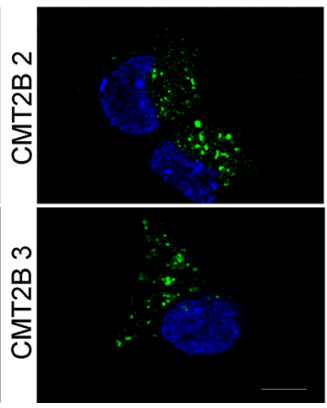

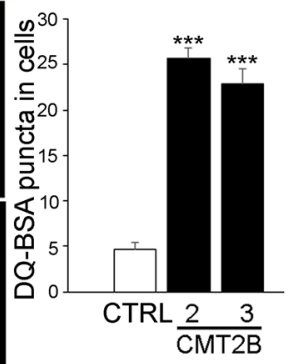

Fig. 9 Lysosomal activity in iPSC-derived sensory neurons. a Lysates of neurons derived from controls and CMT2B fibroblasts carrying the RAB $7^{\mathrm{V} 162 \mathrm{M}}$ mutation (patient 2 and 3 ) were subjected to immunoblotting using anti-LAMP1 and anti- $\beta$-actin antibodies. Intensities of bands were measured by densitometry and normalized against $\beta$-actin. Data represent the mean \pm SEM of three experiments. Statistical analysis was performed using Student's $t$ test with control neurons as referring sample. ${ }^{*} p<0.05$. b Control and CMT2B neurons from patient 2 were fixed and immunolabeled with anti-LAMP1 and anti-peripherin antibodies followed by Alexa488- and Alexa568conjugated secondary antibody respectively while nuclei were stained with DAPI. Bars $10 \mu \mathrm{m}$. LAMP1 intensities were measured using ImageJ and Corrected Total Cell Fluorescence (CTCF) was calculated. Data represent the mean \pm SEM of at least 50 cells ana- lyzed. Student's $t$ test was used for statistical analysis. ${ }^{* * *} p<0.001$. c Lysates of neurons derived from controls and CMT2B fibroblasts (patient 2 and 3) were subjected to immunoblotting using anti-cathepsin D and anti- $\beta$-actin antibodies. Intensities of bands were measured by densitometry and normalized against $\beta$-actin. Data represent the mean \pm SEM of three experiments. Statistical analysis was performed using Student's $t$ test with control neurons as referring sample. ${ }^{*} p<0.05$. d Control and CMT2B neurons from patient 2 and 3 were treated with DQ-BSA for $24 \mathrm{~h}$, then fixed, labeled with DAPI and observed on a confocal microscope. Bars $10 \mu \mathrm{m}$. DQ-BSA puncta in cells were measured using ImageJ. Data represent the mean \pm SEM of at least 50 cells analyzed. For DQ-BSA quantification, Student's $t$ test was used for statistical analysis. $* * * p<0.001$

neuropathies, including CMT1A and CMT1E in which mutations in PMP22 (peripheral myelin protein 22) disrupt the initiation of autophagy [89]. However, despite these premises, autophagy modulation as a treatment for hereditary neuropathies remains elusive [89]. Our present data widen the current knowledge about pathomechanisms of CMT2B, demonstrating changes in the expression of different proteins along the endocytic degradative pathway that could become targets to revert the disease phenotype.

This study has been performed on skin fibroblasts from three CMT2B patients with the RAB7 ${ }^{\mathrm{V} 162 \mathrm{M}}$ mutation and on iPS-derived sensory neurons of two patients. Although these data are consistent with previous and present data obtained on continuous cell lines transfected with plasmids for expression of CMT2B-causing RAB7 mutant proteins, the number of patients is very limited, due to the fact 


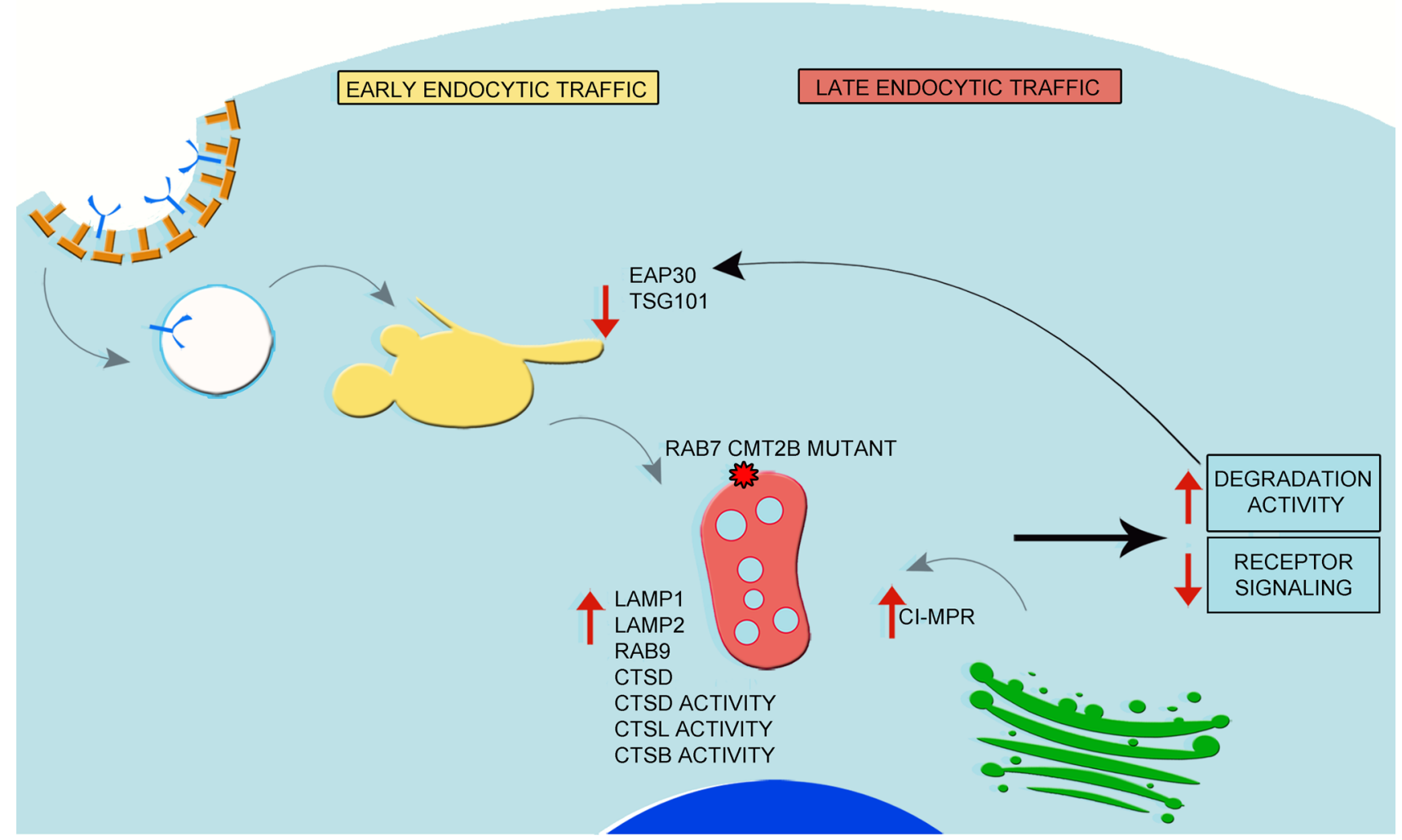

Fig. 10 Model of the Impact of the CMT2B-causing RAB7 mutant protein on the endocytic pathway. In CMT2B the presence of $\mathrm{RAB} 7^{\mathrm{V} 162 \mathrm{M}}$ causes an increase of late endosomal proteins and enzymes as well as of lysosomal activity. This, in turn, activates a feedback control mechanism demonstrated by the decrease of ESCRT proteins. Because of the presence of the RAB7 mutant, CMT2B cells fail to respond to this regulatory mechanism, showing higher lysosomal activity that CMT2B is a rare form of a rare disease. Furthermore, the three patients were from a single family and there may be modifier variants in this family. Thus, it is fundamental to expand in the future the number of patient cell lines to strengthen our findings.

Acknowledgements We thank Mariangela Stasi for technical help in some of the experiments and for the initial drawing of Fig. 10, and ALEMBIC (San Raffaele Institute, Milan, Italy) for support with imaging analyses. Electron microscopy samples were processed and analyzed in the Electron Microscopy Laboratory, Institute of Biomedicine, University of Turku. We thank Jenni Laine and Markus Peurla for technical assistance.

Author contributions $\mathrm{CB}, \mathrm{LS}$ and SCP conceived the study. $\mathrm{CB}$ and SCP supervised the study. CB, RR, MDL, SCP and EE designed the experiments. RR, CR, MDL, RT, RB and EE performed the experiments. CB, RR, CR, MDL, RT, FM, MN, SCP and EE analyzed the data. $\mathrm{CB}$ wrote the paper. RR, CR, MDL and EE prepared the figures. All authors reviewed, edited and approved the final manuscript.

Funding The work was supported by Fondazione Telethon (Grant GGP16037 to CB, SCP and LS), by Associazione Italiana per la Ricerca sul Cancro (AIRC), Investigator Grant 2016N. 19068 to $\mathrm{CB}$ ) and by the Academy of Finland (Grant to E-LE). RR was also supported by Consorzio Interuniversitario Biotecnologie (CIB) with a travel grant.

\section{Compliance with ethical standards}

Conflict of interest The authors declare that the research was conducted in the absence of any commercial or financial relationships that could be construed as a potential conflict of interest.

Open Access This article is licensed under a Creative Commons Attribution 4.0 International License, which permits use, sharing, adaptation, distribution and reproduction in any medium or format, as long as you give appropriate credit to the original author(s) and the source, provide a link to the Creative Commons licence, and indicate if changes were made. The images or other third party material in this article are included in the article's Creative Commons licence, unless indicated otherwise in a credit line to the material. If material is not included in the article's Creative Commons licence and your intended use is not permitted by statutory regulation or exceeds the permitted use, you will need to obtain permission directly from the copyright holder. To view a copy of this licence, visit http://creativecommons.org/licenses/by/4.0/. 


\section{References}

1. Huotari J, Helenius A (2011) Endosome maturation. EMBO J 30:3481-3500

2. Irannejad R, Tsvetanova NG, Lobingier BT, von Zastrow M (2015) Effects of endocytosis on receptor-mediated signaling. Curr Opin Cell Biol 35:137-143

3. Jovic M, Sharma M, Rahajeng J, Caplan S (2010) The early endosome: a busy sorting station for proteins at the crossroads. Histol Histopathol 25:99-112

4. Guerra F, Bucci C (2016) Multiple roles of the small GTPase Rab7. Cells 5(3):E34

5. Girard E, Chmiest D, Fournier N, Johannes L, Paul JL, Vedie B, Lamaze C (2014) Rab7 is functionally required for selective cargo sorting at the early endosome. Traffic 15:309-326

6. Bucci C, Thomsen P, Nicoziani P, McCarthy J, van Deurs B (2000) Rab7: a key to lysosome biogenesis. Mol Biol Cell 11(2):467-480

7. Harrison R, Bucci C, Vieira O, Schroer T, Grinstein S (2003) Phagosomes fuse with late endosomes and/or lysosomes by extension of membrane protrusions along microtubules: role of Rab7 and RILP. Mol Cell Biol 23(18):6494-6506

8. Jager S, Bucci C, Tanida I, Ueno T, Kominami E, Saftig P, Eskelinen EL (2004) Role for Rab7 in maturation of late autophagic vacuoles. J Cell Sci 117(20):4837-4848

9. Kawauchi T (2011) Regulation of cell adhesion and migration in cortical neurons: not only Rho but also Rab family small GTPases. Small GTPases 2(1):36-40

10. Tang BL (2016) Rab, Arf, and Arl-regulated membrane traffic in cortical neuron migration. J Cell Physiol 231:1417-1423

11. Bucci C, Alifano P, Cogli L (2014) The role of Rab proteins in neuronal cells and in the trafficking of neurotrophin receptors. Membranes 4:642-677

12. Deinhardt K, Salinas S, Verastegui C, Watson R, Worth D, Hanrahan S, Bucci C, Schiavo G (2006) Rab5 and Rab7 control endocytic sorting along the axonal retrograde transport pathway. Neuron 52(2):293-305

13. Saxena S, Bucci C, Weis J, Kruttgen A (2005) The small GTPase Rab7 controls the endosomal trafficking and neuritogenic signaling of the nerve growth factor receptor TrkA. J Neurosci 25(47):10930-10940

14. Kawauchi T, Sekine K, Shikanai M, Chihama K, Tomita K, Kubo K, Nakajima K, Nabeshima Y, Hoshino M (2010) Rab GTPases-dependent endocytic pathways regulate neuronal migration and maturation through $\mathrm{N}$-cadherin trafficking. Neuron 67(4):588-602

15. Cogli L, Progida C, Thomas CL, Spencer-Dene B, Donno C, Schiavo G, Bucci C (2013) Charcot-Marie-Tooth type 2B disease-causing RAB7A mutant proteins show altered interaction with the neuronal intermediate filament peripherin. Acta Neuropathol 25(2):257-272

16. Cogli L, Progida C, Bramato R, Bucci C (2013) Vimentin phosphorylation and assembly are regulated by the small GTPase Rab7a. Biochim Biophys Acta 1833:1283-1293

17. Helfand BT, Mendez MG, Pugh J, Delsert C, Goldman RD (2003) A role for intermediate filaments in determining and maintaining the shape of nerve cells. Mol Biol Cell 14:5069-5081

18. Styers ML, Salazar G, Love R, Peden AA, Kowalczyk AP, Faundez V (2004) The endo-lysosomal sorting machinery interacts with the intermediate filament cytoskeleton. Mol Biol Cell 15:5369-5382

19. Shea TB, Beermann ML, Fischer I (1993) Transient requirement for vimentin in neuritogenesis: intracellular delivery of antivimentin antibodies and antisense oligonucleotides inhibit neurite initiation but not elongation of existing neurites in neuroblastoma. J Neurosci Res 36:66-76

20. Troy CM, Muma NA, Greene LA, Price DL, Shelanski ML (1990) Regulation of peripherin and neurofilament expression in regenerating rat motor neurons. Brain Res 529(1-2):232-238

21. Dubey M, Hoda S, Chan WK, Pimenta A, Ortiz DD, Shea TB (2004) Reexpression of vimentin in differentiated neuroblastoma cells enhances elongation of axonal neurites. J Neurosci Res 78:245-249

22. Reid AJ, Welin D, Wiberg M, Terenghi G, Novikov LN (2010) Peripherin and ATF3 genes are differentially regulated in regenerating and non-regenerating primary sensory neurons. Brain Res 1310:1-7

23. Schreij AM, Fon EA, McPherson PS (2016) Endocytic membrane trafficking and neurodegenerative disease. Cell Mol Life Sci 73:1529-1545

24. Meggouh F, Bienfait HM, Weterman MA, de Visser M, Baas F (2006) Charcot-Marie-Tooth disease due to a de novo mutation of the RAB7 gene. Neurology 67(8):1476-1478

25. Houlden H, King RH, Muddle JR, Warner TT, Reilly MM, Orrell RW, Ginsberg L (2004) A novel RAB7 mutation associated with ulcero-mutilating neuropathy. Ann Neurol 56:586-590

26. Verhoeven K, De Jonghe P, Coen K, Verpoorten N, Auer-Grumbach M, Kwon JM, FitzPatrick D, Schmedding E, De Vriendt E, Jacobs A, Van Gerwen V, Wagner K, Hartung HP, Timmerman V (2003) Mutations in the small GTP-ase late endosomal protein RAB7 cause Charcot-Marie-Tooth type 2B neuropathy. Am J Hum Genet 72:722-727

27. Wang X, Han C, Liu W, Wang P, Zhang X (2014) A novel RAB7 mutation in a Chinese family with Charcot-Marie-Tooth type 2B disease. Gene 534:431-434

28. Ajroud-Driss S, Deng HX, Siddique T (2011) Recent advances in the genetics of hereditary axonal sensory-motor neuropathies type 2. Curr Neurol Neurosci Rep 11(3):262-273

29. Reilly MM, Murphy SM, Laurá M (2011) Charcot-Marie-Tooth disease. J Peripher Nerv Syst 16(1):1-14

30. Barisic N, Claeys KG, Sirotković-Skerlev M, Löfgren A, Nelis E, De Jonghe P, Timmerman V (2008) Charcot-Marie-Tooth disease: a clinico-genetic confrontation. Ann Hum Genet 72(3):416-441

31. Bucci C, Bakke O, Progida C (2012) Charcot-Marie-Tooth disease and intracellular traffic. Prog Neurobiol 99:191-225

32. Bucci C, De Luca M (2012) Molecular basis of Charcot-MarieTooth type 2B disease. Biochem Soc Trans 40(6):1368-1372

33. Manganelli F, Pisciotta C, Provitera V, Taioli F, Iodice R, Topa A, Fabrizi GM, Nolano M, Santoro L (2012) Autonomic nervous system involvement in a new CMT2B family. J Peripher Nerv Syst 17(3):361-364

34. McCray BA, Skordalakes E, Taylor JP (2010) Disease mutations in Rab7 result in unregulated nucleotide exchange and inappropriate activation. Hum Mol Genet 19(6):1033-1047

35. De Luca A, Progida C, Spinosa MR, Alifano P, Bucci C (2008) Characterization of the Rab7K157N mutant protein associated with Charcot-Marie-Tooth type 2B. Biochem Biophys Res Commun 372(2):283-287

36. Spinosa MR, Progida C, De Luca A, Colucci AMR, Alifano P, Bucci C (2008) Functional characterization of Rab7 mutant proteins associated with Charcot-Marie-Tooth type 2B disease. J Neurosci 28(7):1640-1648

37. Janssens K, Goethals S, Atkinson D, Ermanoska B, Fransen E, Jordanova A, Auer-Grumbach M, Asselbergh B, Timmerman V (2014) Human Rab7 mutation mimics features of CharcotMarie-Tooth neuropathy type 2B in Drosophila. Neurobiol Dis 65:211-219. https://doi.org/10.1016/j.nbd.2014.01.021

38. Cherry S, Jin EJ, Ozel MN, Lu Z, Agi E, Wang D, Jung WH, Epstein D, Meinertzhagen IA, Chan CC, Hiesinger PR (2013) 
Charcot-Marie-Tooth 2B mutations in rab7 cause dosagedependent neurodegeneration due to partial loss of function. Elife 2:e01064. https://doi.org/10.7554/eLife.01064

39. Ponomareva OY, Eliceiri KW, Halloran MC (2016) CharcotMarie-Tooth $2 b$ associated Rab7 mutations cause axon growth and guidance defects during vertebrate sensory neuron development. Neural Dev 11(1):2

40. Cogli L, Progida C, Lecci R, Bramato R, Krüttgen A, Bucci C (2010) CMT2B-associated Rab7 mutants inhibit neurite outgrowth. Acta Neuropathol 120(4):491-501

41. Yamauchi J, Torii T, Kusakawa S, Sanbe A, Nakamura K, Takashima S, Hamasaki H, Kawaguchi S, Miyamoto Y, Tanoue A (2010) The mood stabilizer valproic acid improves defective neurite formation caused by Charcot-Marie-Tooth disease-associated mutant Rab7 through the JNK signaling pathway. J Neurosci Res 88(14):3189-3197

42. BasuRay S, Mukherjee S, Romero E, Wilson MC, WandingerNess A (2010) Rab7 mutants associated with Charcot-MarieTooth disease exhibit enhanced NGF-stimulated signaling. PLoS ONE 5(12):e15351

43. Colecchia D, Stasi M, Leonardi M, Manganelli F, Nolano M, Veneziani BM, Santoro L, Eskelinen EL, Chiariello M, Bucci C (2018) Alterations of autophagy in the peripheral neuropathy Charcot-Marie-Tooth type 2B. Autophagy 14(6):930-941. https://doi.org/10.1080/15548627.2017.1388475

44. Lee G, Chambers SM, Tomishima MJ, Studer L (2010) Derivation of neural crest cells from human pluripotent stem cells. Nat Protoc 5(4):688-701. https://doi.org/10.1038/nprot.2010.35

45. Chambers SM, Qi Y, Mica Y, Lee G, Zhang XJ, Niu L, Bilsland J, Cao L, Stevens E, Whiting P, Shi SH, Studer L (2012) Combined small-molecule inhibition accelerates developmental timing and converts human pluripotent stem cells into nociceptors. Nat Biotechnol 30(7):715-720. https://doi.org/10.1038/nbt.2249

46. Clark AJ, Kaller MS, Galino J, Willison HJ, Rinaldi S, Bennett DLH (2017) Co-cultures with stem cell-derived human sensory neurons reveal regulators of peripheral myelination. Brain 140(4):898-913. https://doi.org/10.1093/brain/awx012

47. Bucci C, Parton RG, Mather IH, Stunnenberg H, Simons K, Hoflack B, Zerial M (1992) The small GTPase rab5 functions as a regulatory factor in the early endocytic pathway. Cell 70:715-728

48. Gorvel JP, Chavrier P, Zerial M, Gruenberg J (1991) Rab5 controls early endosome fusion in vitro. Cell 64:915-925

49. van der Sluijs P, Hull M, Webster P, Mâle P, Goud B, Mellman I (1992) The small GTP-binding protein rab4 controls an early sorting event on the endocytic pathway. Cell 70(5):729-740

50. Ganley IG, Carroll K, Bittova L, Pfeffer S (2004) Rab9 GTPase regulates late endosome size and requires effector interaction for its stability. Mol Biol Cell 15(12):5420-5430

51. Gruenberg J, Stenmark H (2004) The biogenesis of multivesicular endosomes. Nat Rev Mol Cell Biol 5:317-323

52. Mallet WG, Maxfield FR (1999) Chimeric forms of furin and TGN38 are transported with the plasma membrane in the transGolgi network via distinct endosomal pathways. J Cell Biol 146:345-359

53. Banting G, Ponnambalam S (1997) TGN38 and its orthologues: roles in post-TGN vesicle formation and maintenance of TGN morphology. Biochim Biophys Acta 1355(3):209-217

54. Williams RL, Urbe $S$ (2007) The emerging shape of the ESCRT machinery. Nat Rev Mol Cell Biol 8(5):355-368. https://doi. org/10.1038/nrm2162

55. Benes P, Vetvicka V, Fusek M (2008) Cathepsin D-many functions of one aspartic protease. Crit Rev Oncol Hematol 68:12-28

56. Zaidi N, Maurer A, Nieke S, Kalbacher H (2008) Cathepsin D: a cellular roadmap. Biochem Biophys Res Commun 376:5-9
57. Richo G, Conner GE (1991) Proteolytic activation of human procathepsin D. Adv Exp Med Biol 306:289-296

58. Basuray S, Mukherjee S, Seaman MN, Wandinger-Ness A (2013) Rab7 mutants associated with Charcot-Marie-Tooth disease cause delayed growth factor receptor transport and altered endosomal and nuclear signaling. J Biol Chem 288:1135-1149

59. Wee P, Wang Z (2017) Epidermal growth factor receptor cell proliferation signaling pathways. Cancers (Basel) 9:5. https://doi. org/10.3390/cancers9050052

60. Abdrabou A, Wang Z (2018) Post-translational modification and subcellular distribution of Rac1: an update. Cells 7:12. https://doi. org/10.3390/cells7120263

61. Margiotta A, Progida C, Bakke O, Bucci C (2017) Rab7a regulates cell migration through Rac1 and vimentin. Biochim Biophys Acta 1864:367-381

62. Alaseem A, Alhazzani K, Dondapati P, Alobid S, Bishayee A, Rathinavelu A (2019) Matrix metalloproteinases: a challenging paradigm of cancer management. Semin Cancer Biol 56:100-115. https://doi.org/10.1016/j.semcancer.2017.11.008

63. Zhuge Y, Xu J (2001) Rac1 mediates type I collagen-dependent MMP-2 activation. Role in cell invasion across collagen barrier. J Biol Chem 276(19):16248-16256. https://doi.org/10.1074/jbc. m010190200

64. Manser E, Loo TH, Koh CG, Zhao ZS, Chen XQ, Tan L, Tan I, Leung T, Lim L (1998) PAK kinases are directly coupled to the PIX family of nucleotide exchange factors. Mol Cell 1(2):183192. https://doi.org/10.1016/s1097-2765(00)80019-2

65. Jacquemet G, Morgan MR, Byron A, Humphries JD, Choi CK, Chen CS, Caswell PT, Humphries MJ (2013) Rac1 is deactivated at integrin activation sites through an IQGAP1-filamin-A-RacGAP1 pathway. J Cell Sci 126:4121-4135

66. D’Amico A, Bertini E (2013) Metabolic neuropathies and myopathies. Handb Clin Neurol 113:1437-1455

67. Ginsberg SD, Mufson EJ, Alldred MJ, Counts SE, Wuu J, Nixon RA, Che S (2011) Upregulation of select rab GTPases in cholinergic basal forebrain neurons in mild cognitive impairment and Alzheimer's disease. J Chem Neuroanat 42(2):102-110

68. Cataldo AM, Barnett JL, Pieroni C, Nixon RA (1997) Increased neuronal endocytosis and protease delivery to early endosomes in sporadic Alzheimer's disease: neuropathologic evidence for a mechanism of increased beta-amyloidogenesis. J Neurosci 17:6142-6151

69. Ginsberg SD, Mufson EJ, Counts SE, Wuu J, Alldred MJ, Nixon RA, Che S (2010) Regional selectivity of rab5 and rab7 protein upregulation in mild cognitive impairment and Alzheimer's disease. J Alzheimers Dis 22:631-639

70. Ginsberg SD, Alldred MJ, Counts SE, Cataldo AM, Neve RL, Jiang Y, Wuu J, Chao MV, Mufson EJ, Nixon RA, Che S (2010) Microarray analysis of hippocampal CA1 neurons implicates early endosomal dysfunction during Alzheimer's disease progression. Biol Psychiatry 68(10):885-893

71. Cataldo AM, Hamilton DJ, Barnett JL, Paskevich PA, Nixon RA (1996) Properties of the endosomal-lysosomal system in the human central nervous system: disturbances mark most neurons in populations at risk to degenerate in Alzheimer's disease. J Neurosci 16:186-199

72. Leonard D, Hayakawa A, Lawe D, Lambright D, Bellve KD, Standley C, Lifshitz LM, Fogarty KE, Corvera S (2008) Sorting of EGF and transferrin at the plasma membrane and by cargospecific signaling to EEA1-enriched endosomes. J Cell Sci $121: 3445-3458$

73. Malerød L, Stuffers S, Brech A, Stenmark H (2007) Vps22/EAP30 in ESCRT-II mediates endosomal sorting of growth factor and chemokine receptors destined for lysosomal degradation. Traffic $8: 1617-1629$ 
74. Malerød L, Pedersen NM, Sem Wegner CE, Lobert VH, Leithe E, Brech A, Rivedal E, Liestøl K, Stenmark H (2011) Cargodependent degradation of ESCRT-I as a feedback mechanism to modulate endosomal sorting. Traffic 12:1211-1226

75. Seaman MNJ, Harbour ME, Tattersall D, Read E, Bright N (2009) Membrane recruitment of the cargo-selective retromer subcomplex is catalysed by the small GTPase Rab7 and inhibited by the Rab-GAP TBC1D5. J Cell Sci 122:2371-2382

76. Zhang K, Fishel Ben Kenan R, Osakada Y, Xu W, Sinit RS, Chen L, Zhao X, Chen JY, Cui B, Wu C (2013) Defective axonal transport of Rab7 GTPase results in dysregulated trophic signaling. J Neurosci 33:7451-7462

77. Kalyankrishna S, Grandis JR (2006) Epidermal growth factor receptor biology in head and neck cancer. J Clin Oncol 24(17):2666-2672. https://doi.org/10.1200/JCO.2005.04.8306

78. Citri A, Yarden Y (2006) EGF-ERBB signalling: towards the systems level. Nat Rev Mol Cell Biol 7(7):505-516. https://doi. org/10.1038/nrm1962

79. Huang C, Jacobson K, Schaller MD (2004) MAP kinases and cell migration. J Cell Sci 117(Pt 20):4619-4628. https://doi. org/10.1242/jcs.01481

80. Bunney TD, Katan M (2010) Phosphoinositide signalling in cancer: beyond PI3K and PTEN. Nat Rev Cancer 10(5):342-352. https://doi.org/10.1038/nrc2842

81. Kolsch V, Charest PG, Firtel RA (2008) The regulation of cell motility and chemotaxis by phospholipid signaling. J Cell Sci 121(Pt 5):551-559. https://doi.org/10.1242/jcs.023333

82. Huang C, Park CC, Hilsenbeck SG, Ward R, Rimawi MF, Wang YC, Shou J, Bissell MJ, Osborne CK, Schiff R (2011) Beta1 integrin mediates an alternative survival pathway in breast cancer cells resistant to lapatinib. Breast Cancer Res 13(4):R84. https:// doi.org/10.1186/bcr2936

83. Wertheimer E, Gutierrez-Uzquiza A, Rosemblit C, Lopez-Haber C, Sosa MS, Kazanietz MG (2012) Rac signaling in breast cancer: a tale of GEFs and GAPs. Cell Signal 24(2):353-362. https://doi. org/10.1016/j.cellsig.2011.08.011

84. Lien EC, Dibble CC, Toker A (2017) PI3K signaling in cancer: beyond AKT. Curr Opin Cell Biol 45:62-71. https://doi. org/10.1016/j.ceb.2017.02.007

85. Sabra H, Brunner M, Mandati V, Wehrle-Haller B, Lallemand D, Ribba AS, Chevalier G, Guardiola P, Block MR, Bouvard D (2017) beta1 integrin-dependent Rac/group I PAK signaling mediates YAP activation of Yes-associated protein 1 (YAP1) via NF2/merlin. J Biol Chem 292(47):19179-19197. https://doi. org/10.1074/jbc.M117.808063

86. Ganley IG, Wong PM, Jiang X (2011) Thapsigargin distinguishes membrane fusion in the late stages of endocytosis and autophagy. Autophagy 7:1397-1399

87. Ganley IG, Wong PM, Gammoh N, Jiang X (2011) Distinct autophagosomal-lysosomal fusion mechanism revealed by thapsigargin-induced autophagy arrest. Mol Cell 42:731-743

88. Ponomareva OY, Eliceiri KW, Halloran MC (2016) Charcot-Marie-Tooth 2b associated Rab7 mutations cause axon growth and guidance defects during vertebrate sensory neuron development. Neural Dev 11:2. https://doi.org/10.1186/s1306 4-016-0058-x

89. Haidar M, Timmerman V (2017) Autophagy as an emerging common pathomechanism in inherited peripheral neuropathies. Front Mol Neurosci 10:143

Publisher's Note Springer Nature remains neutral with regard to jurisdictional claims in published maps and institutional affiliations. 